\title{
Research Paper: The Main Factors Affecting the Acceptance and Adaptation With Spinal Cord Injury: A Qualitative Study
}

\section{Mohammad Saeed Khanjani ${ }^{1}{ }^{\circledR}$, ${ }^{*}$ Hamid Reza Khanekeh ${ }^{2}$ (D), Seyyed Jalal Younesi ${ }^{1}$, Manouchehr Azkhosh $^{1}$}

1. Department of Counseling, University of Social Welfare and Rehabilitation Sciences, Tehran, Iran.

2. Department of Nursing, University of Social Welfare and Rehabilitation Sciences, Tehran, Iran.

\begin{tabular}{|c|c|}
\hline $\begin{array}{l}\text { Sus your device tos scan } \\
\text { and read the article online }\end{array}$ & Critertion Khanjani MS, Khanekeh HR, Younesi SJ, Azkhosh M. [The Main Factors Affecting the Acceptance and Adapta- \\
\hline 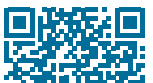 & $\begin{array}{l}\text { tion With Spinal Cord Injury: A Qualitative Study (Persian)]. Archives of Rehabilitation. 2019; 19(4):276-291. http://dx.doi. } \\
\text { org/10.32598/rj.19.4.276 }\end{array}$ \\
\hline ' & doil'http://dx.doi.org/10.32598/rj.19.4.276 \\
\hline
\end{tabular}

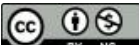

Received: 10 Jun 2018 Accepted: 25 Oct 2018 Available Online: 01 Jan 2019

Keywords:

Acceptance, Adjustment, Spinal cord injury

\section{ABSTRACT}

Objective Spinal cord injury is one of traumatic events that has considerable impact on the quality of life of the injured patients. Not all people react similarly in facing unpleasant event in life. This reaction cold be affected by different factors. Some people after the traumatic event are unable to do normal functions for several years and show some chronic dysfunctions, while others try hard for months, reach some level of adaptation, and show a model of recovery and improvement after tolerating some suffering. Individuals after spinal cord injury tend to adapt and cope with their injuries. However, there are differences in the level of compatibility and coping with injury and some remain vulnerable to some psychological problems. This incompatibility, in addition to the experience of emotional distress can affect other functional areas such as physical health and increase the risk of secondary complications. The purpose of this study was to explore factors affecting the acceptance and adaptation with spinal cord injury based on the experiences of these patients.

Materials \& Methods This qualitative study was conducted using content analysis method. Content analysis is a qualitative method to associate data with the main subject and its final product is the concepts and categories of the study subject. The study participants comprised 23 patients with spinal cord injury in Tehran City, Iran, that were selected purposefully, with a maximum variation in age, levels of education and experiences and roles in life. The inclusion criteria were spinal cord injury, over 18 years old, at least one year passed from the time of injury, and their desire for sharing their experiences on the study subject. Purposive sampling was continued to reach the saturation point in every concept so that more new information could not be found about these concepts. The study data were collected through in depth semi-structured interviews during 2016, and were analyzed using content analysis.

Results The results of the data analysis were led to the extraction of the facilitators and obstacles of acceptance and adaptation in patients with spinal injuries. Facilitators were classified in eight main categories, including the correct support, communication with peers, social participation, spiritual belief, positive attitude, motivators, access to facilities and contextual factors. The obstacles were classified also in two general categories or concepts. Category of social and cultural incorrect beliefs with subcategories such as, pity, negative feedback of relatives, and insufficient knowledge about correct support. The second category comprised structural and contextual obstacles, including subcategories of health-related problems, urban handicap, financial problems, inefficiency of supporting organizations, and unawareness of disabled people.

Conclusion The results obtained from the experiences of patients with spinal cord injury showed that a collection of individual factors, environmental and social factors can affect the process of acceptance and adjustment with injury, and take the role of facilitator or inhibitor during the process of acceptance and adapting with the lesion. Identifying these factors that have been achieved with regard to social context and real experiences of people from exposure to spinal cord injury, can have effective application in designing psychological rehabilitation programs for these people and their families. By promoting the individual and environmental facilitator factors, the process of accepting and coping with injury can be facilitated. In addition delays in acceptance and compatibility and negative psychological side effects can also be prevented by reducing the impact of inhibitory factors.

\section{* Corresponding Author:}

Hamid Reza Khankeh, PhD.

Address: Department of Nursing, University of Social Welfare and Rehabilitation Sciences, Tehran, Iran.

Tel: +98 (21) 22180061

E-Mail: hamid.khankeh@ki.se 


\title{
تبيين عوامل مؤثر بر بذيرش و سازگًارى با ضايعه نخاعى: يك مطالعه كيفى
}

\author{
محمدسعيد خانجانى' (ه)، • حميدرضا خانكه' ث، سيد جلال يونسى'، منوجهر ازخوش'
}

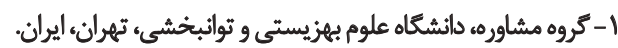

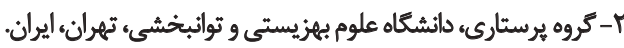

\begin{abstract}
حكبد

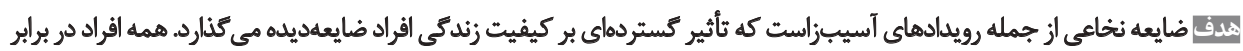

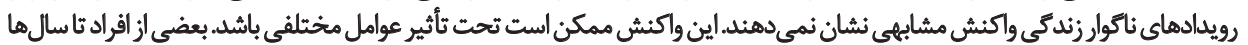

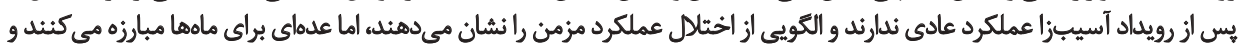

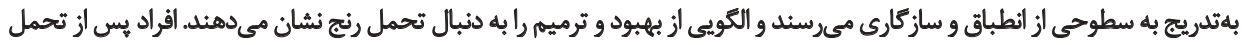

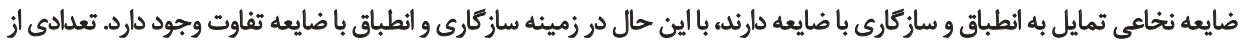

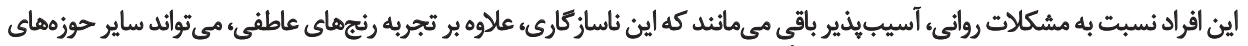

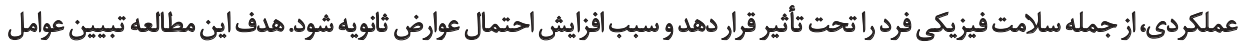

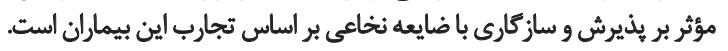

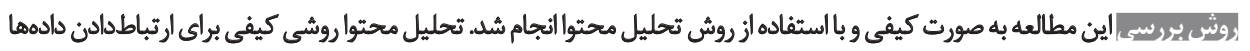

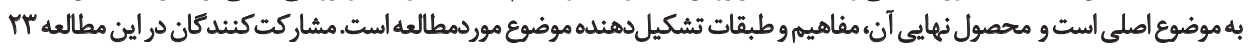

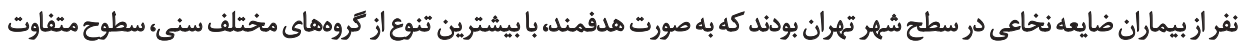

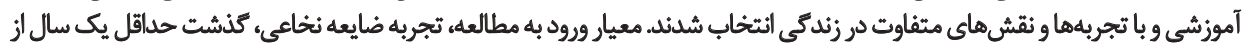

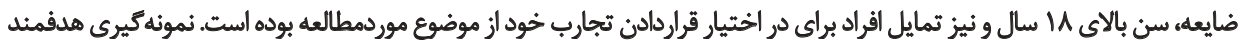

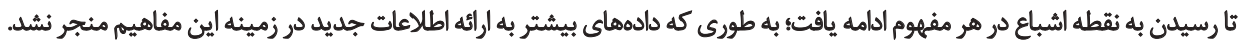

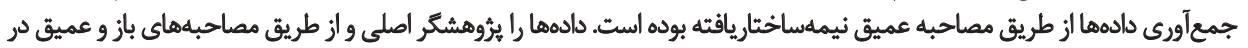

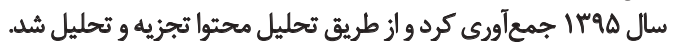

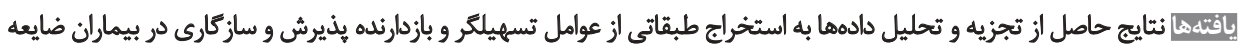

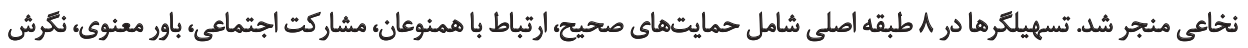

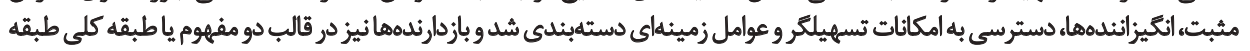

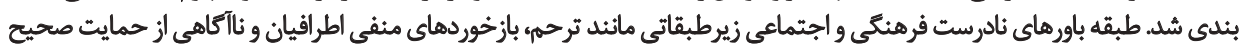

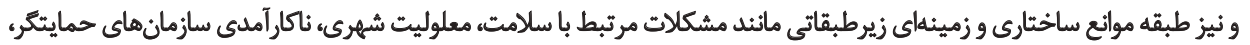

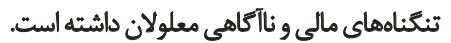

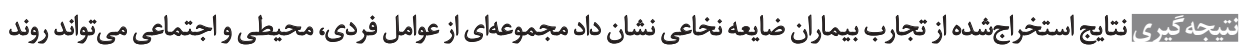

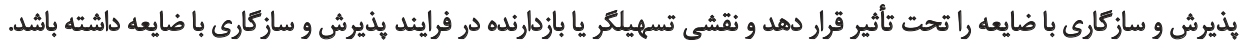

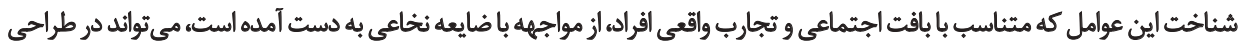

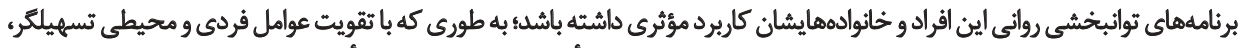

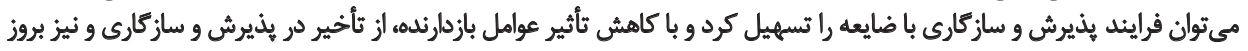
عوارض روانى مثفى جلوكيرى كرد.
\end{abstract}

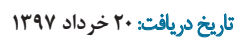

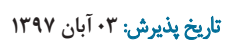

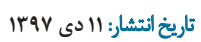

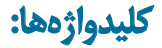

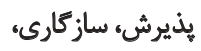

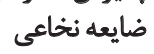


مطالعات نشان داده است بذيرش عاملى كليدى در فرايند بهبود

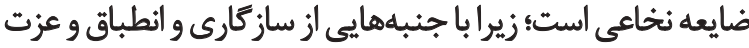

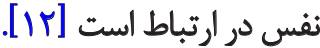

سازكارى با ناتواني، فرايند عمومى تحول يوياست كه از اين

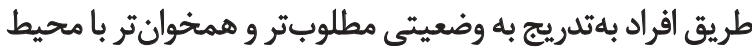

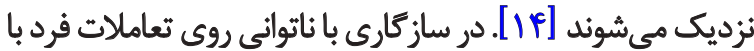

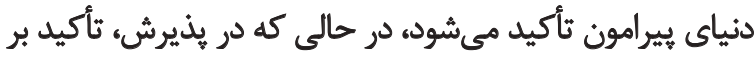

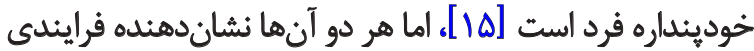

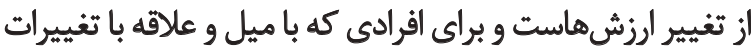

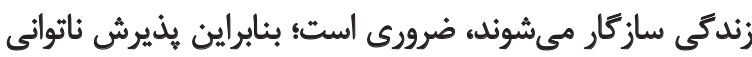

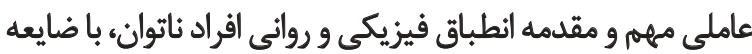

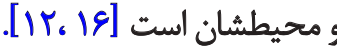

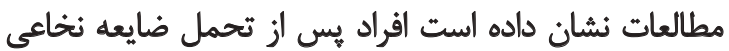

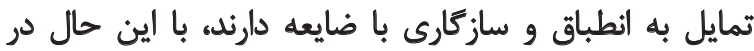

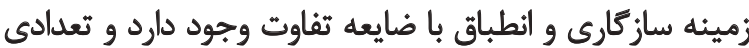

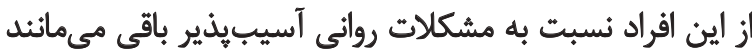

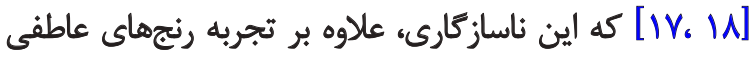

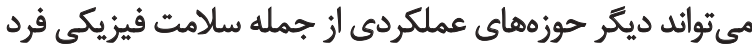

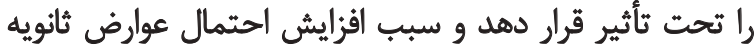

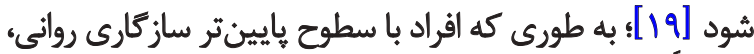

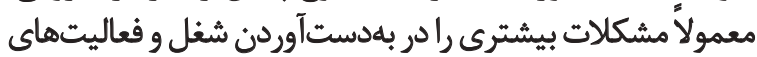

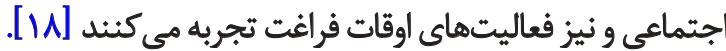

مطالعات كذشته اغلب به مشكلات جسمى و روانى متعاقب

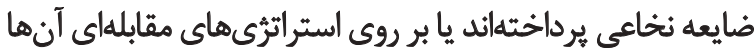

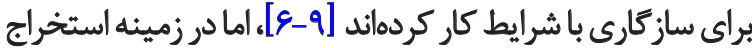

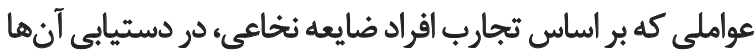

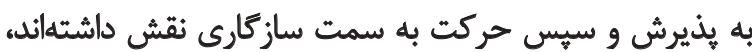

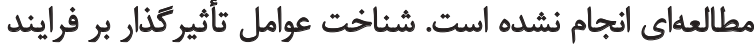

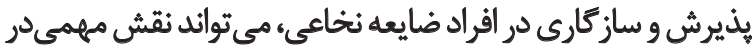

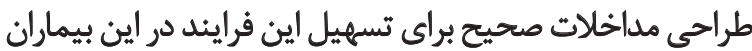

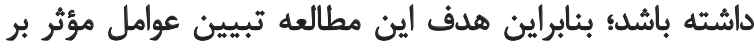

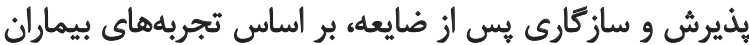

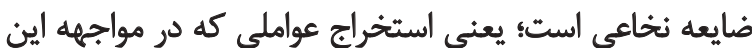

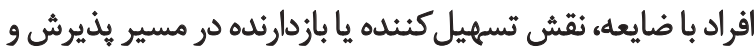
سازكًارى مثبت باضايعه داشته است.

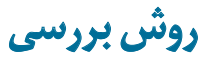

اين مطالعه با رويكرد كيفى و با روش تحليل محتوا انجام

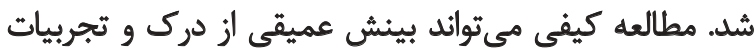

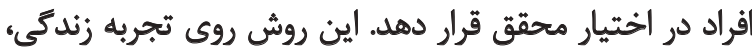

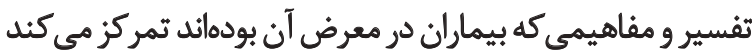

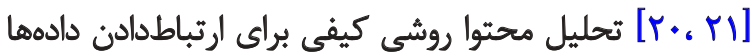
به موضوع اصلى است و محصول نهايى آنه مفاهيم و طبقاط آنقات
مقدمه

ضايعه نخاعي از جمله رويدادهاي آسيبزا در سراسر جهان

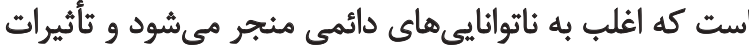

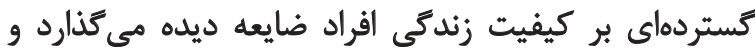

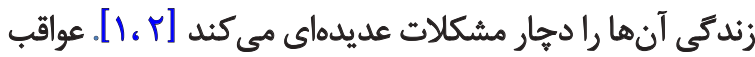

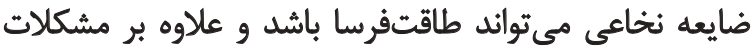

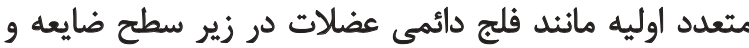

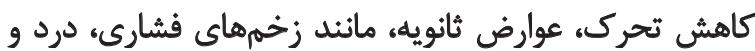

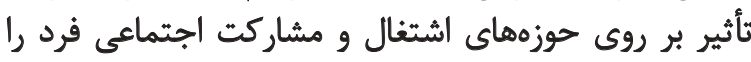

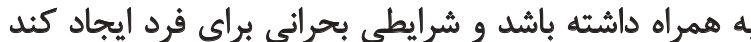

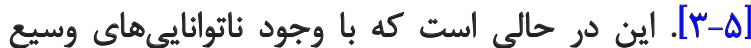

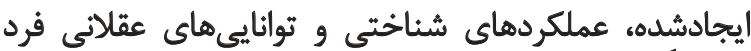

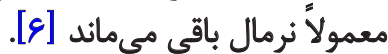

علاوه بر مشكلات جسمى و ويامدهاى آن، افراد ضايعه

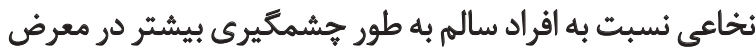

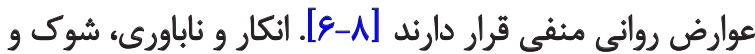

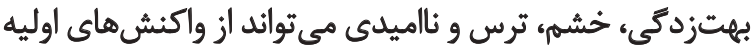

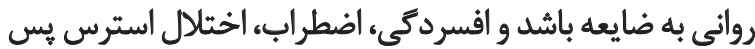

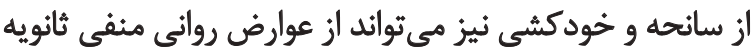

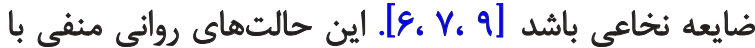

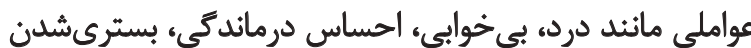

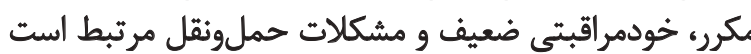

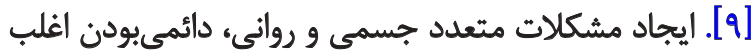

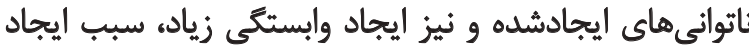

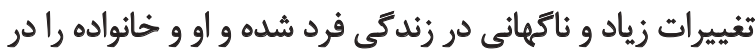

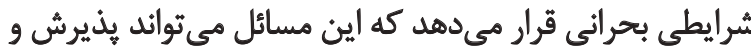
سازكارى با ضايعه را با مشكل مواجيه كند.

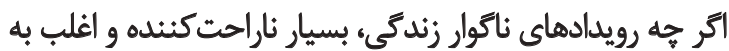

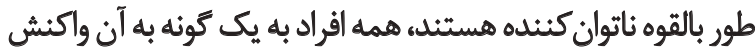

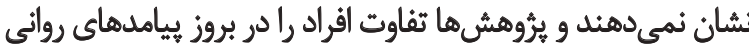

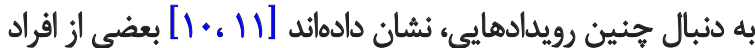

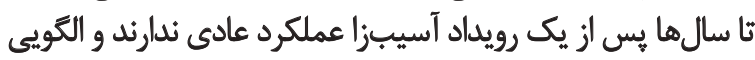

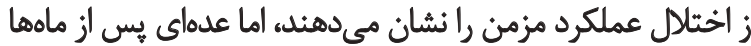

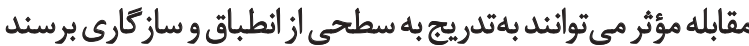

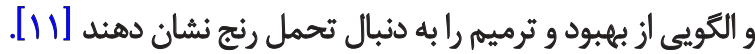

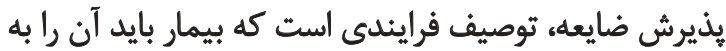

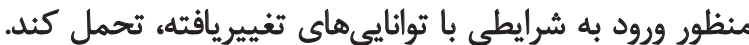

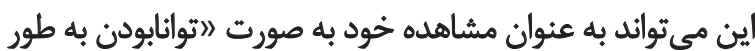

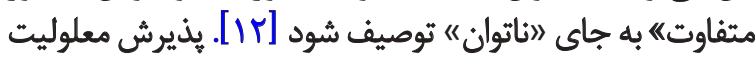

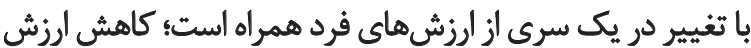

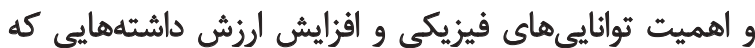

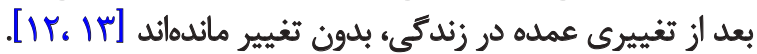


روايى و اعثبار ياقتهها

براي افزايش روايي و اعتبار يافتهها مراحل زير انجام شد: ارتباط

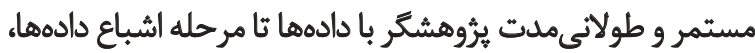

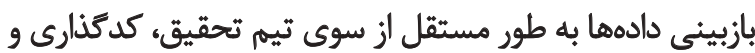

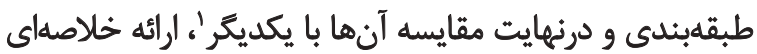

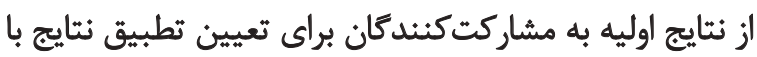

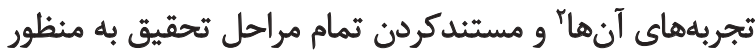
ايجاد قابليث استفاده براى محققان ديكر.

يافتهها

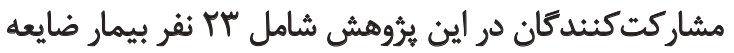

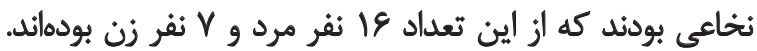

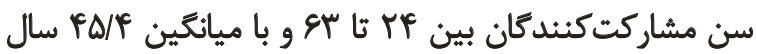

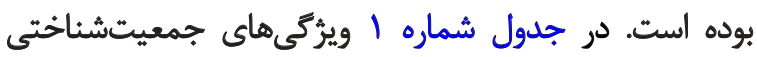

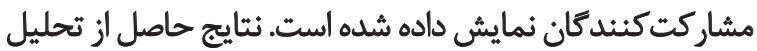

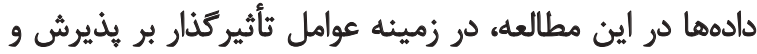

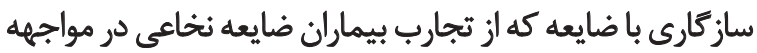

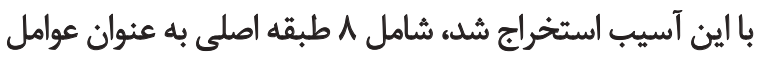

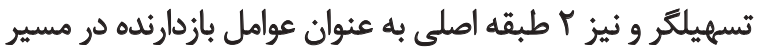
يذيرش و سازكارى باضايعه بوده است. عوامل تسهيلكّر بذيرش و سازئارى

\section{حمايتهاىصحيح}

از مهمثرين عوامل ثأثيركذار مثبت در تجارب اين بيماران،

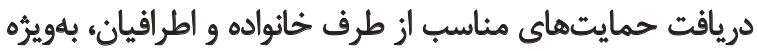

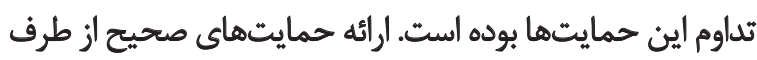

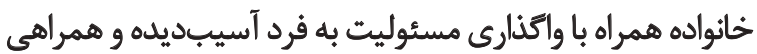

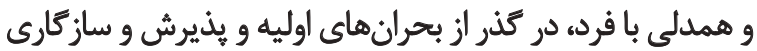

$$
\text { با وايعه بسيار ثأثير تذذار بوده است. }
$$

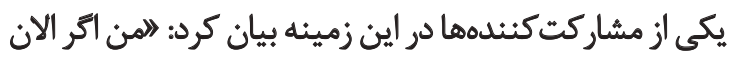

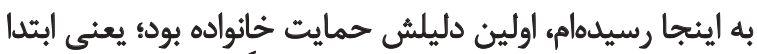

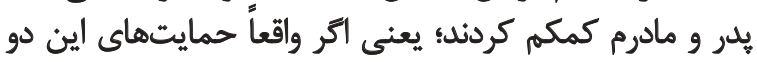

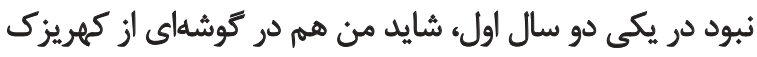

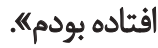

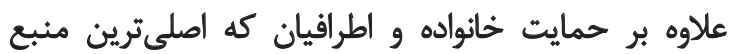

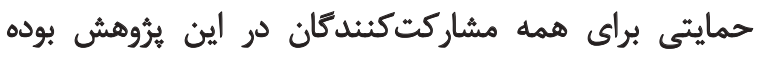

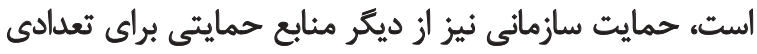

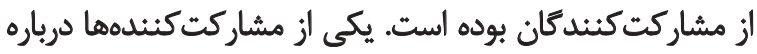
حمايت سازمان محل كارش بيان كرد: الاسازماني كه در آن كار كار

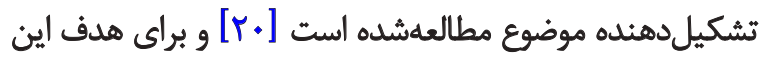

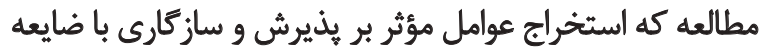

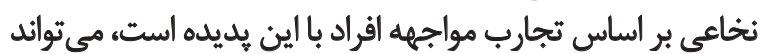

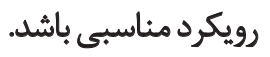

مشاركت كنئدكّان

مشاركت كنيدكان در اين مطالعه بr نفر از بيماران ضايعه

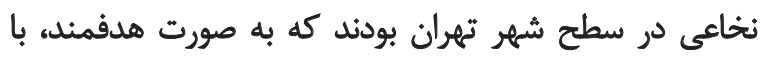

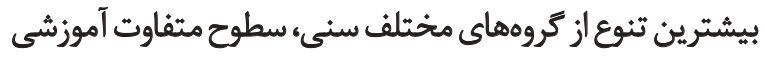

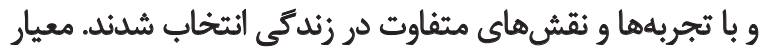

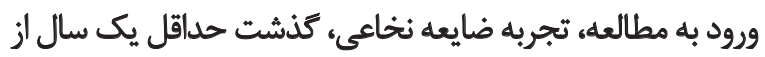

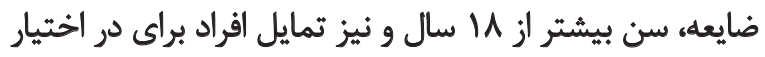

قراردادن تجارب خود درباره موضوع موردمطالعه بوده است آن.

\section{جمعآورى دادهها}

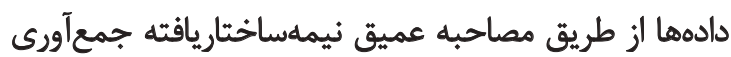

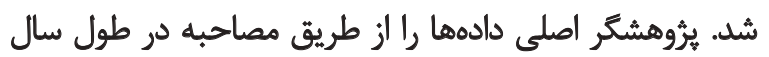

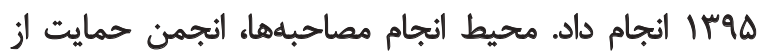

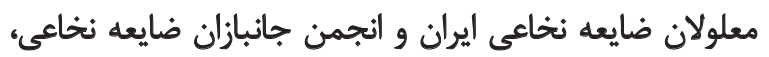

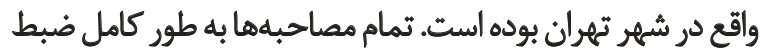

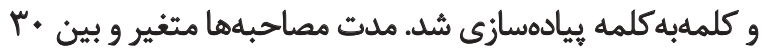

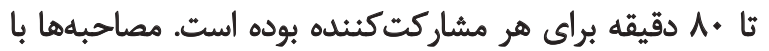

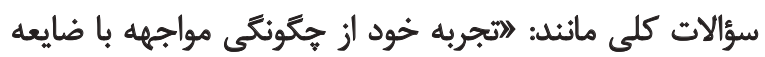

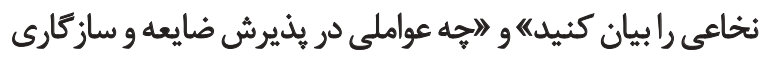

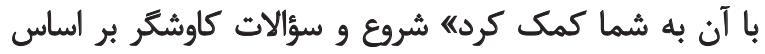

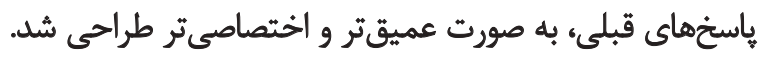

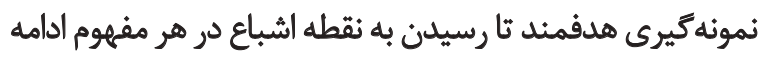

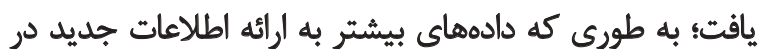
زمينه اين مفاهيم منجر نشد.

تحليل دادهها

در اين مطالعه كيفى براى تجزيه و تحليل دادهها از تحليل

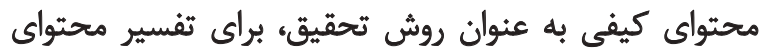

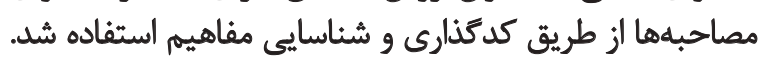

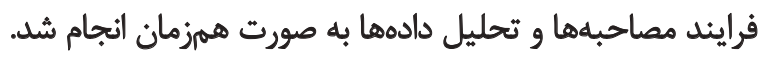

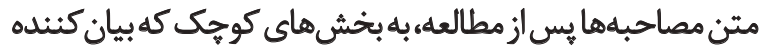

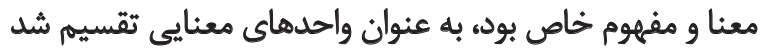

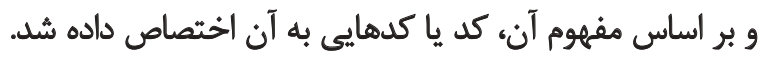

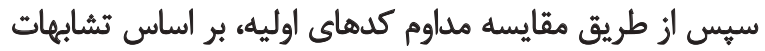

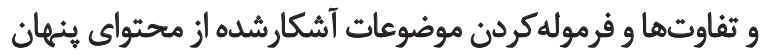
متن مصاحبهها، زيرطبقات و طبقات اصلى مطالعه شكل كرفت 
جدول ا. مشخصات جمعيتشئاختي مشاركت كنيدكان

\begin{tabular}{|c|c|c|c|c|c|c|}
\hline وضعيت تأهل & مدت ضايعه (سال) & سطح ضايعه & علت ضايعه & تحصيلات & جنس & سن \\
\hline مجرد & $\pi$ & سينهاى & تصادف & دييلم & نز & ra \\
\hline متاهل & 11 & سيثلاى & تصادف & كارشناسى & نن & $r$. \\
\hline متاهل & 9 & سينهاى & تصادف & كارشناسىارشد & مرد & rV \\
\hline متاهل & $\pi$ & سيئه اى & جانباز & كارشناسىارشد & مرد & g. \\
\hline متأهل & $\wedge$ & سينهاى & تومور نخاع & كارشناسىارشد & مرد & ar \\
\hline متأهل & 1. & كرنى & تصادف & كارشناسى & مرد & Tr \\
\hline مجرد & rr & سينهاى & تصادف & كارشناسيعارشد & مرد & il \\
\hline متاهل & $\pi$ & سينهاى & جانباز & يزشك & مرد & $\Delta r$ \\
\hline مجرد & iv & سيثلهاى & ويروس نخاعى & دانشجوى كارشناسى & مرد & $m$ \\
\hline متاهل & $\pi$ & سيتهاى & جانباز & كارشناسىارشد & مرد & ar \\
\hline متأهل & $\pi$ & سيثلهاى & جانباز & كارشتاسى & مرد & $\Delta \Delta$ \\
\hline مجرد & $\Delta$ & سيثلهاى & تصادف & كارشناسى & مرد & re \\
\hline متأهل & rr & سينهاى & اصابت كلوله & كارشناسى & مرد & io \\
\hline مجرد & $r$ & سينهاى & تصادف & كارشناسىارشد & مرد & $\pi$ \\
\hline متاهل & rq & كرنى & تصادف & كارشناسى & زن & il \\
\hline مجرد & $M$ & سينهاى & تصادف & دييلم & مرد & ra \\
\hline متأهل & ir & سينهاى & جانباز & كارشتاسى & مرد & Po \\
\hline متاهل & $r$ & كمرى & تصادف & دييله & زن & rq \\
\hline متاهل & m & سينهاى & جانباز & يزئشك & مرد & $\Delta v$ \\
\hline متاهل & 19 & سيثلهاى & تصادف & دانشجوى كارشناسى & زن & ه. \\
\hline مجرد & $\checkmark$ & كردنى (يارزى) & تصادف & كارشناسى & نن & $M^{6}$ \\
\hline متاهل & 9 & سيثلهاى & حمل شى سنكين & دييلم & مرد & $r$. \\
\hline متأهل & 11 & سينهاى & عقونت نخاعى & كارشناسى & زن & D) \\
\hline
\end{tabular}

كنار آمدن بهتر با مشكلات و نيز شناخت ظرفيتهاي خود براى

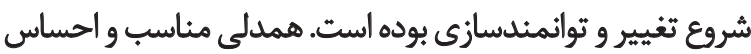

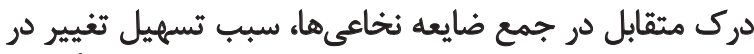

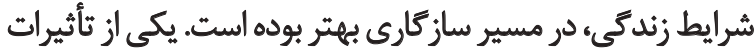

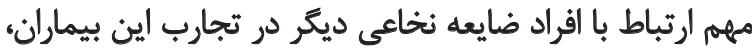

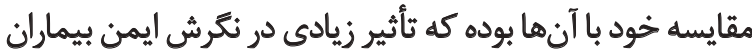

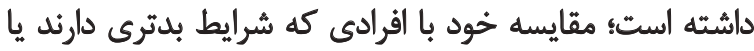

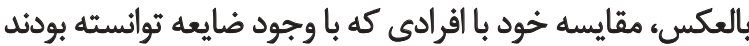
انطباق مناسبى باضايعه داشته باشئد و افراد موفقى باشئد باشئد
مى كردم از نظر ذهنى من را آماده كرد كه شما بايد وارد محيط احتيط

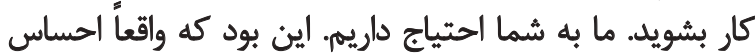

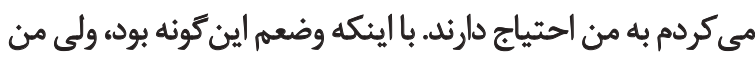

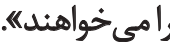

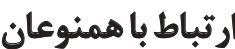

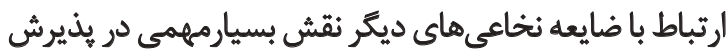

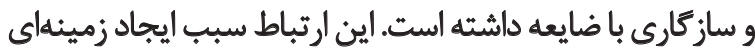
براى بهاشتراكتذارى تجارب و استفاده از تجربه ديكران براى إنيا 


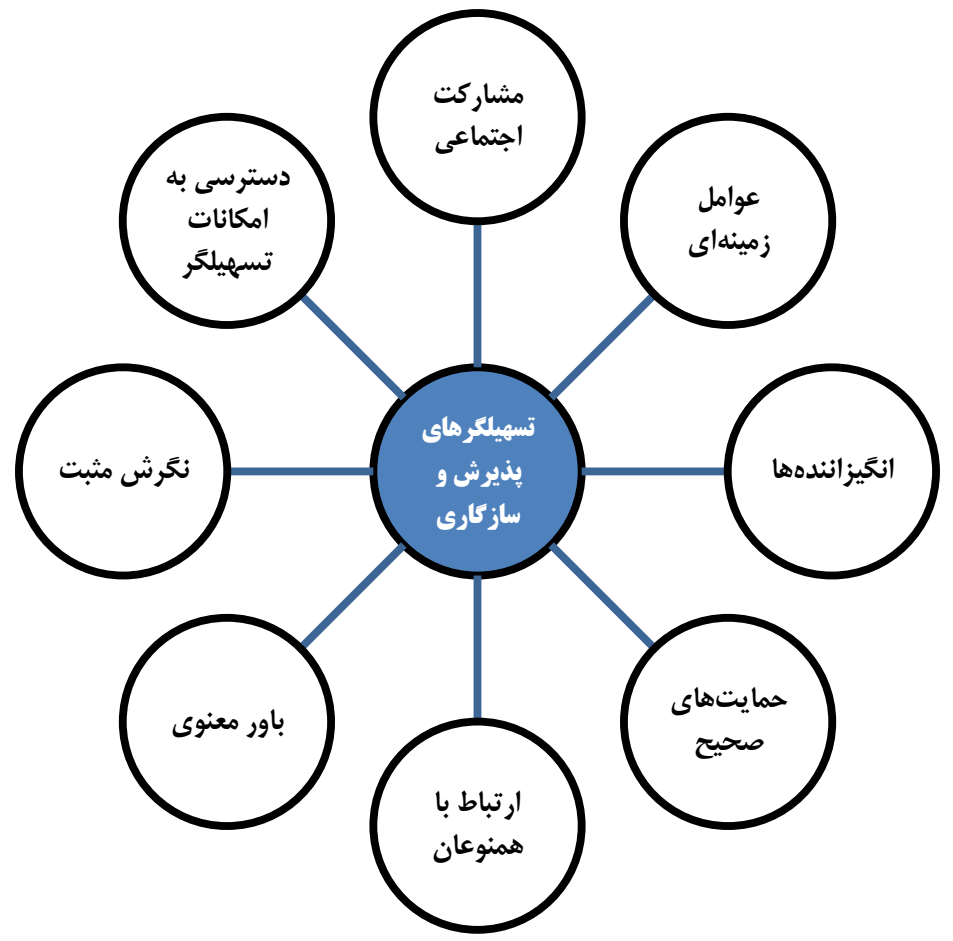

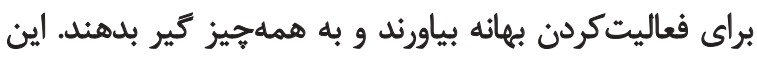

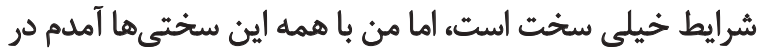

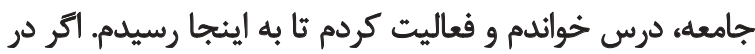

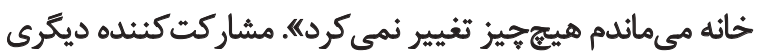

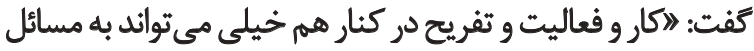

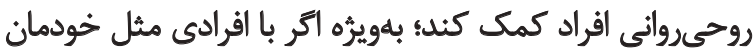

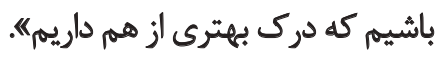

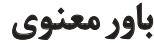

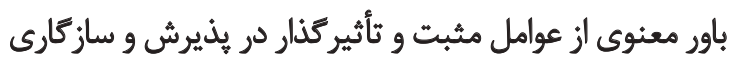

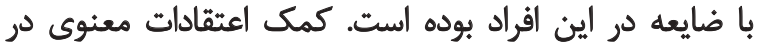

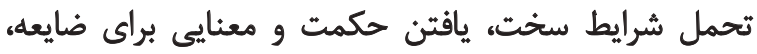

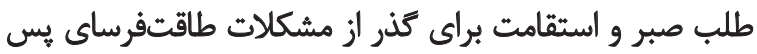

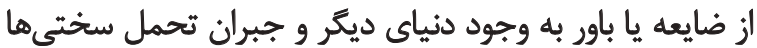

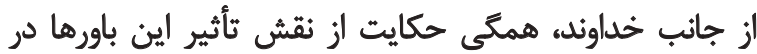

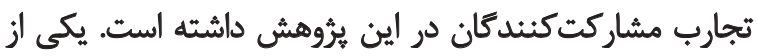

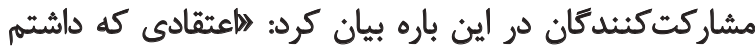

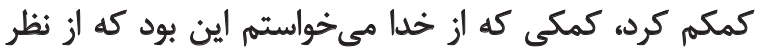

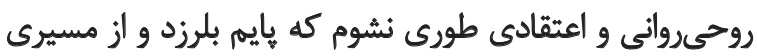

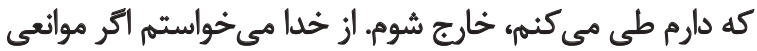

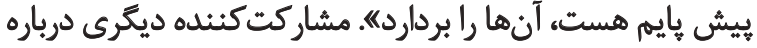

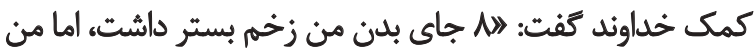

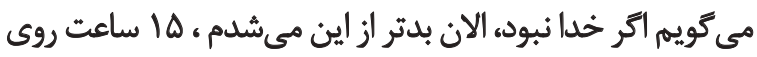

يكى از مشاركت كنيده در زمينه تأثير ارتباط با ديكر ضايعه

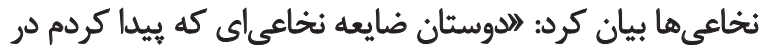

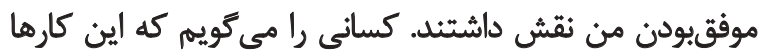

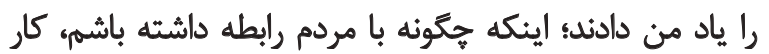

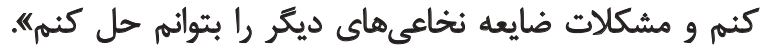

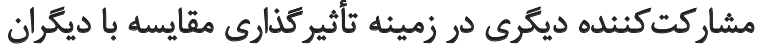

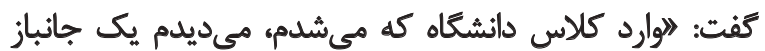

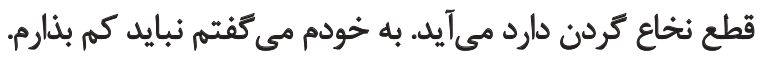

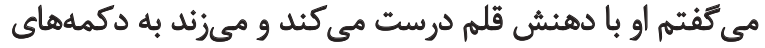

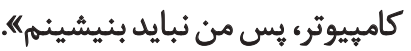

مشاركتاجتماعى

يكى از عوامل مؤثر در سازكارى مناسب با ضايعه، مشاركت

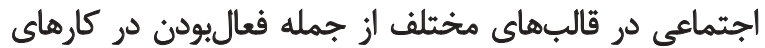

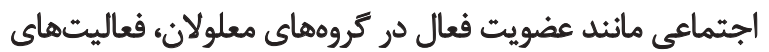

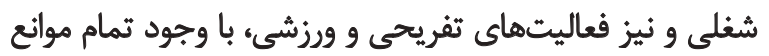

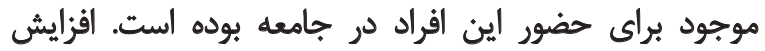

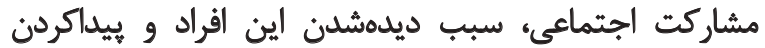

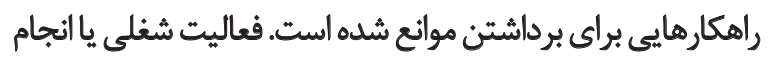

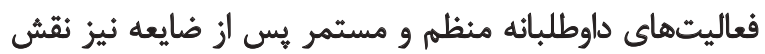

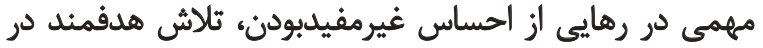
زندگى و بهبود شرايط جسمى و روانى اين افراد داشته است. يكى از مشاركت كنند كان در اين باره بيان كرد: الشايد بعضىها 
ساز كَارى با ضايعه و تلاش براى مفيد و مؤثربودن شرايط را براى تماي

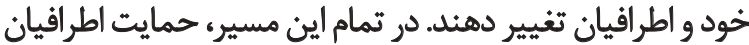

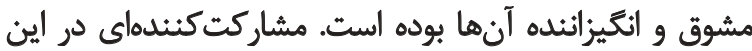

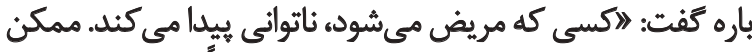

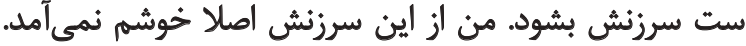

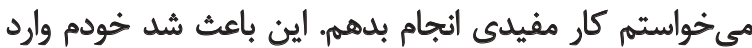

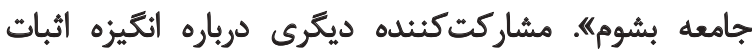

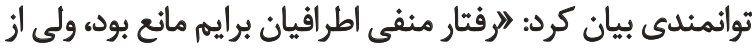

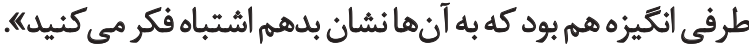

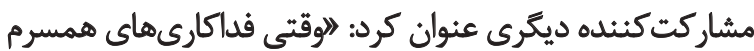

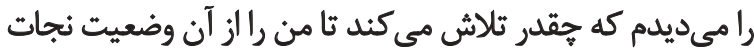

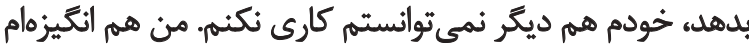

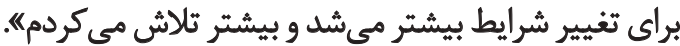

\section{دسترسى به امكانات تسهيلكر}

دسترسى به امكانات مناسب، مناسبسازى محيط زنداتىى،

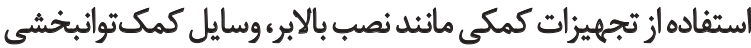

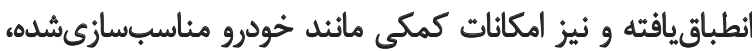

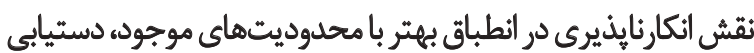

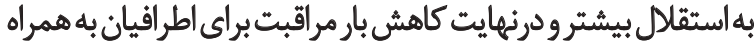

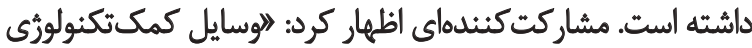

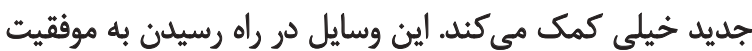

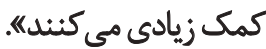

با وجود اهميت دسترسى به اين امكائات انطباقى، بر اساس

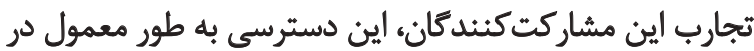

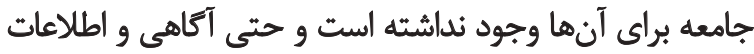

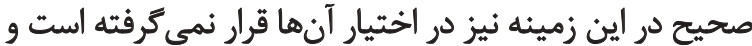

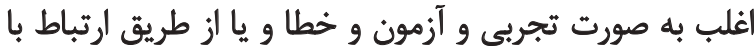

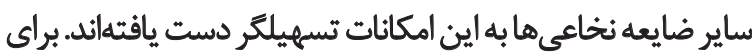

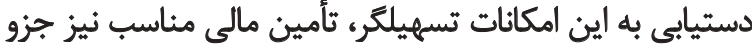

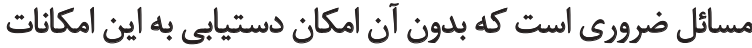

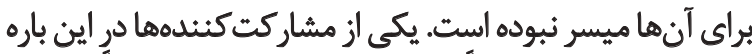

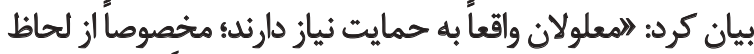

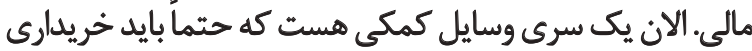

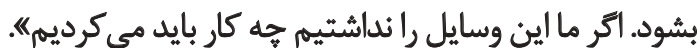

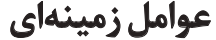

بر اساس تجارب افراد، برخى از ويرثى هاى فردى قبل از

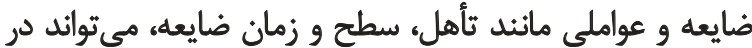

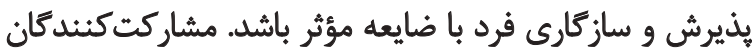

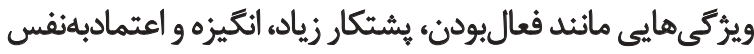

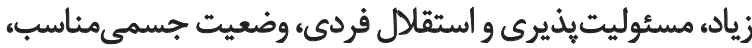
معنوىبودن، مردمدارى و تحصيلات قبل از ضايعه را در مواجهيه

$$
\text { ويلجر بودن كار هر كسى نيست. اين بزركى خداست ه. }
$$

توجه به حكمت و معناي زندكى در عين داشتن ضايعه،

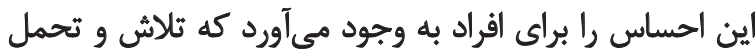

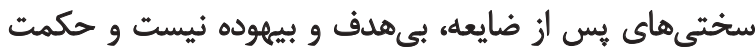

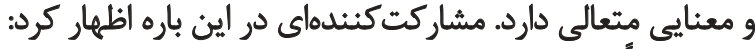

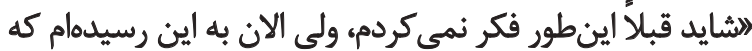

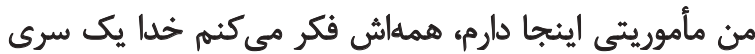

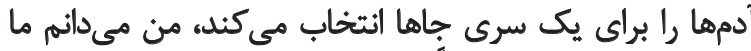

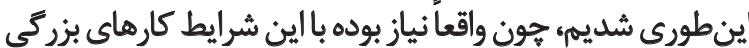

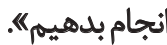

ن تكرش مثبت

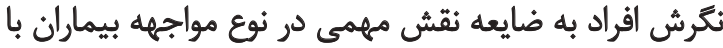

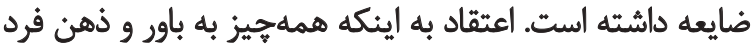

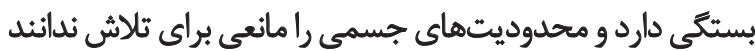

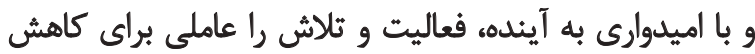

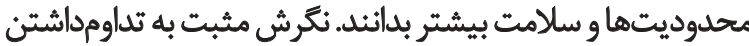

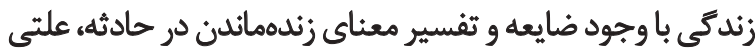

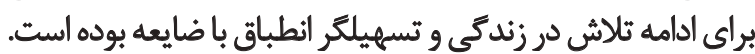

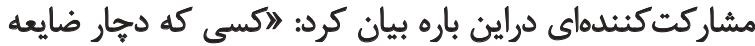

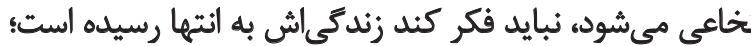

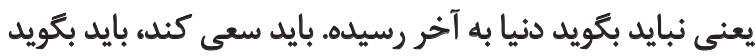

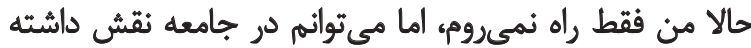

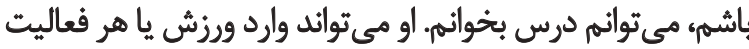

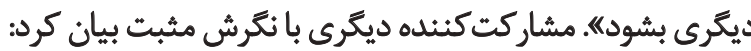

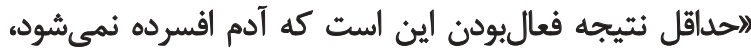

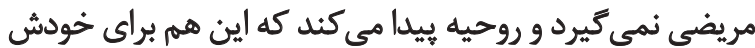

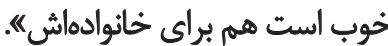

انتيزانندهها

از عوامل كمك كنئده به بذيرش و سازكارى افراد با ضايعه،

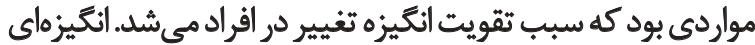

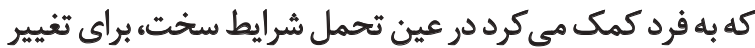

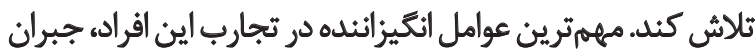

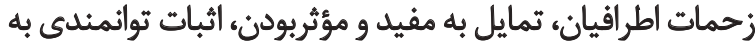

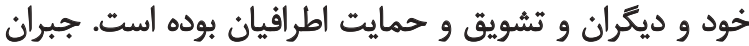

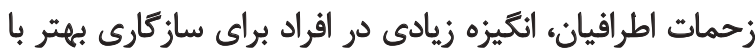

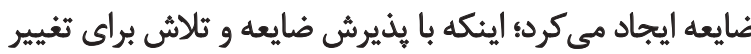

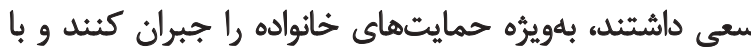
ايجاد تغيير مثبت در خود، فشار جسمى و روانى وارد بر خانئ خانواديه

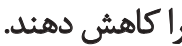

كاهش وابستكى و تغيير وضعيت غيرمفيدبودن نيز از عوامل

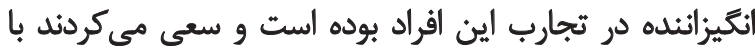




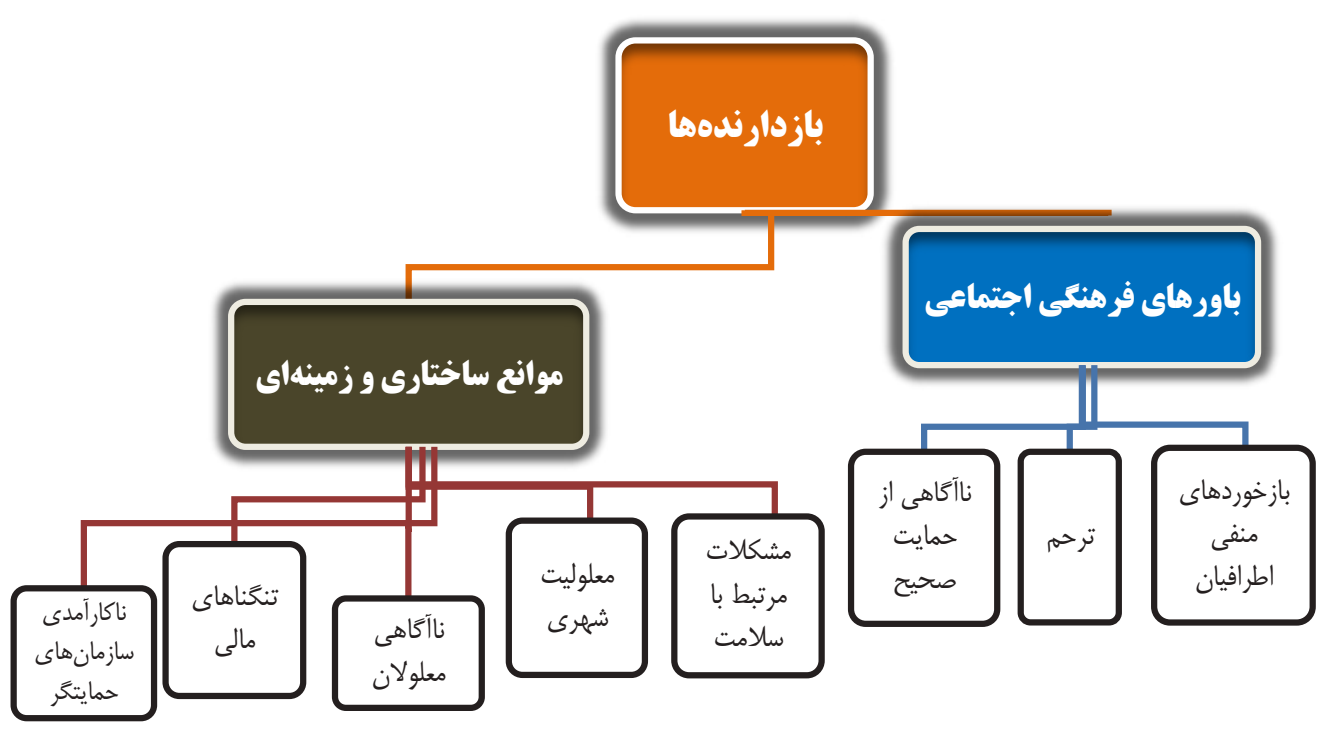

نمى توانيد خلبان بشويد، هيجوقت نمىتوانيد باكايت يرواز كنيده.

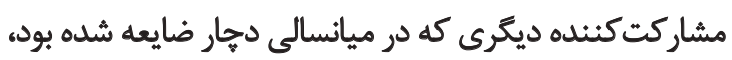

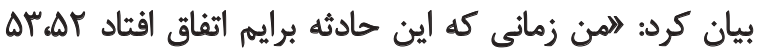

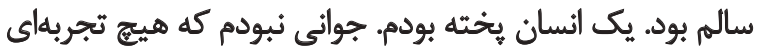

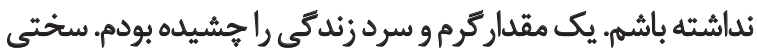

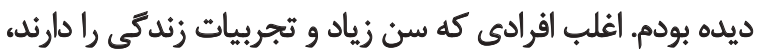

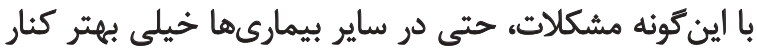

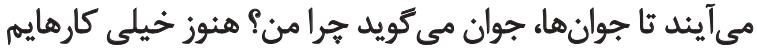

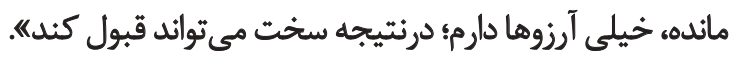
سطح ضايعه نيز از ديد اين افراد در ميزان فعاليتها و عملكرد

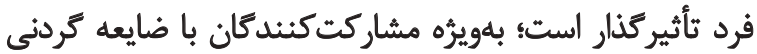

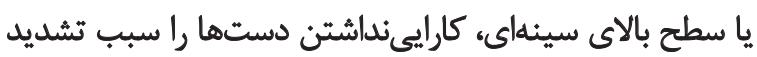

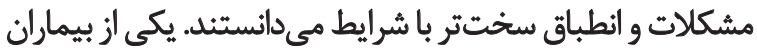

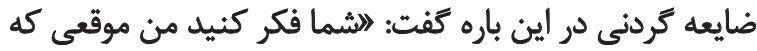

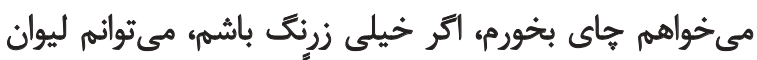

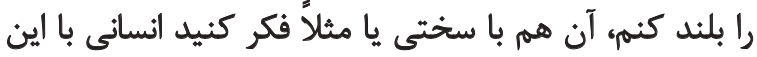

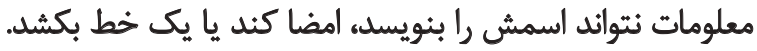

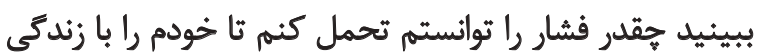
جديد تطبيق بدهمه (تصوير شماره إنمان ).

بازٔهارئدهاها

در كنار عواملى كه در مسير بذيرش و ساز كارى باضايعه نقش

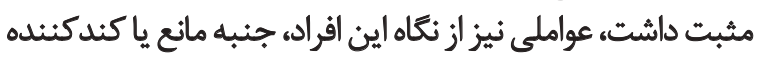

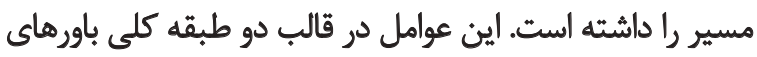

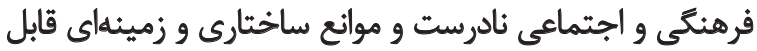

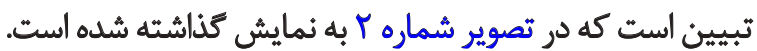

درست با ضايعه و بذيرش و سازخارى با آن، مؤثر و كمككنثده

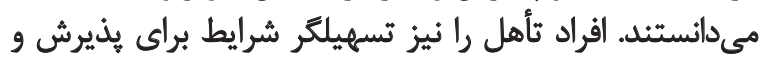

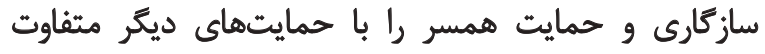

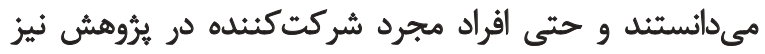

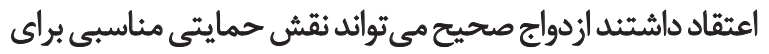

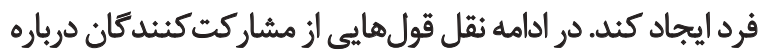

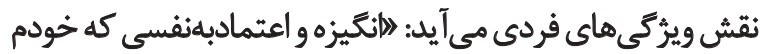

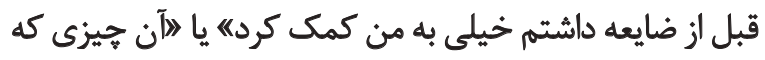

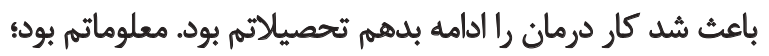

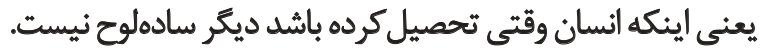

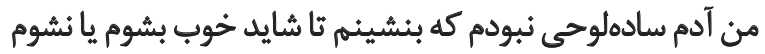

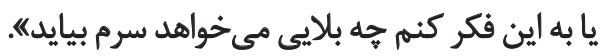

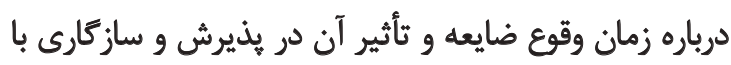

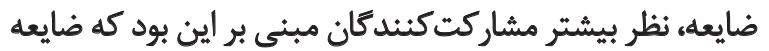

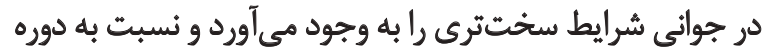

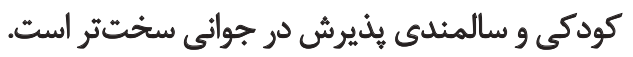

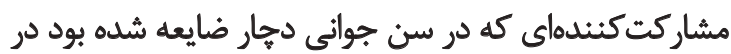

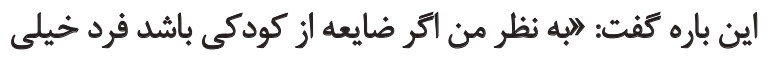

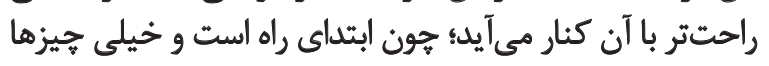

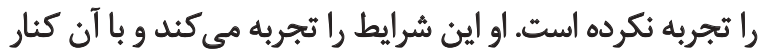

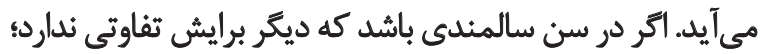

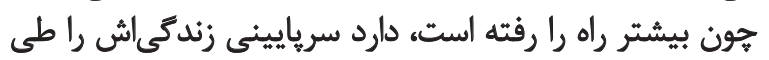

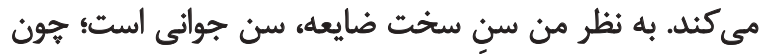

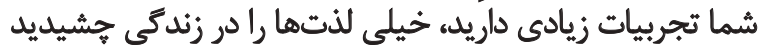

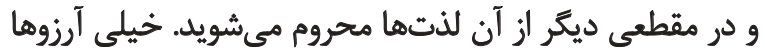

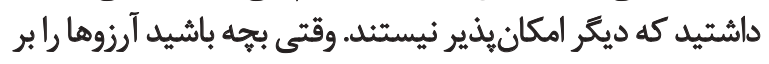

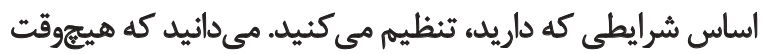




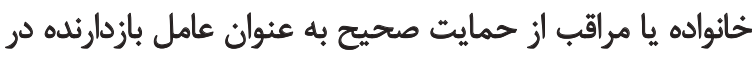

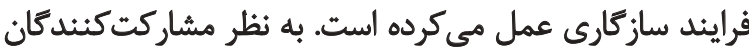

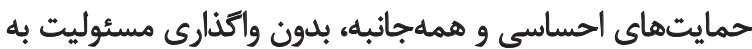

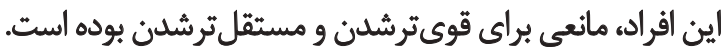

مشاركتكنئدهاي درباره حمايت احساسى و بيش از حرد

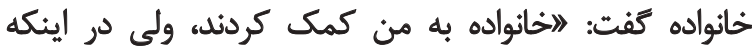

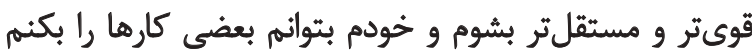

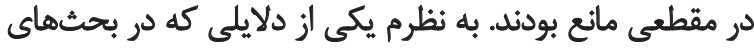

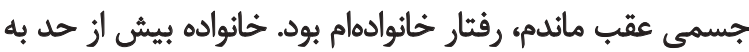

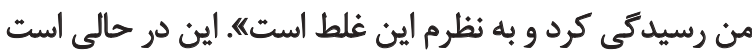

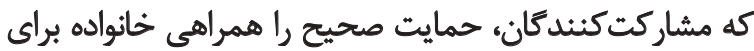

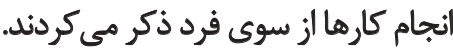

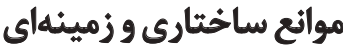

در كنار موانع فرهنگى و اجتماعى كه در ارتباط با باورهاى

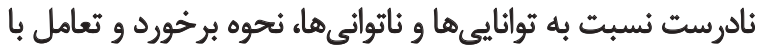

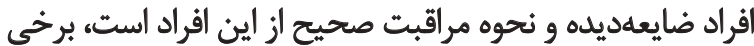

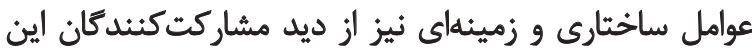

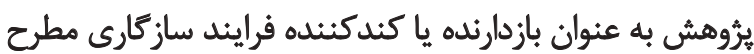

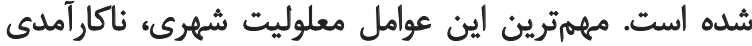

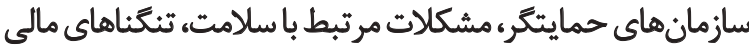

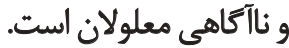

معلوليت شهرى: يكى از موانع كه حضور اين افراد در بستر

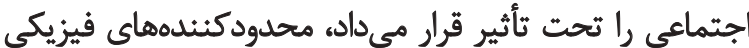

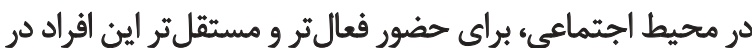

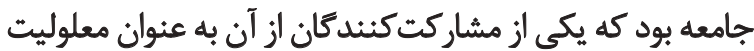

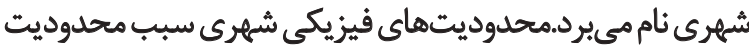

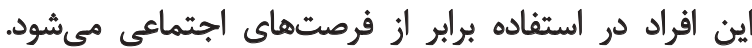

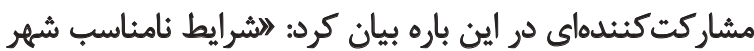

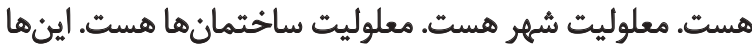
ترمزهايى براى ماست. مانعى است در مسير مائ اينكه بتوانيم راحت

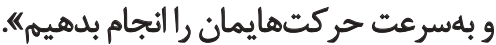

ناكار آمدى سازمانهاى حمايتًّر: ناتوانى سازمانهاى حمايتًّر

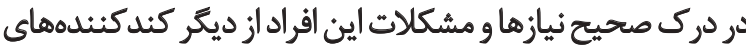

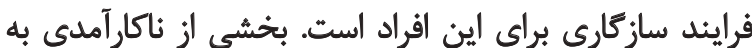

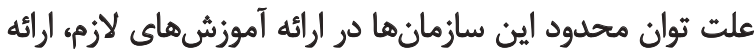

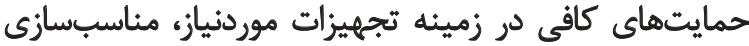

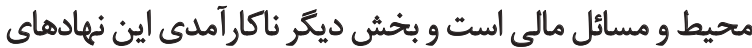

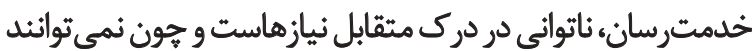

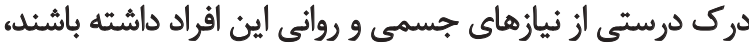

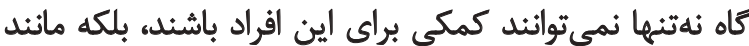
ترمزى براى حركت در مسير سازكارى مناسب عمل نمل مي كنيند.

\section{باور هاى فرهنكى و اجتماعى نادرست}

باورهاي نادرست نسبت به معلولان در خانواده و جامعاده در

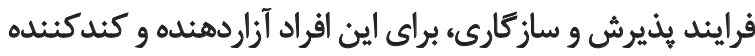

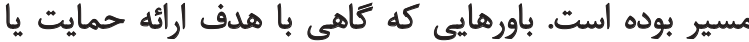

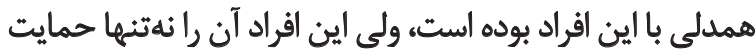

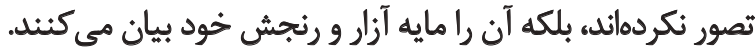

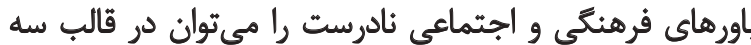

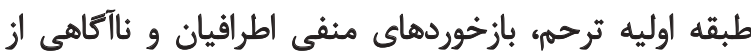
حمايت صحيح توضيح داد.

ترحم: نتاههاى ترحمه آميز ديكران به افراد آسيبديده، ازئ عوامل

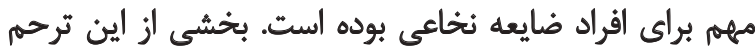

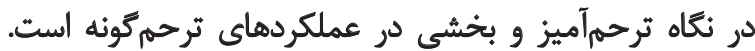

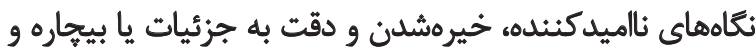

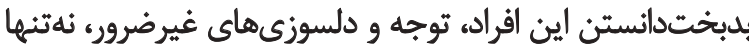

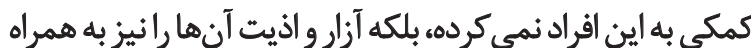

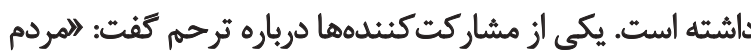

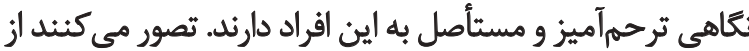
اين افراد كارى از دستشان برنمى آيد، توقعى نبايد داشت دارئ.

از ديد اين افراد كمك واقعى تسهيلكُ شرايط و ترحم، بازٔدارنده

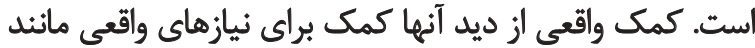

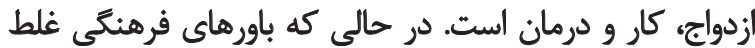

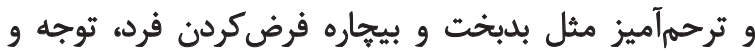

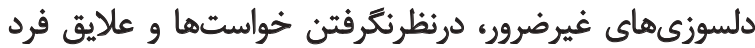

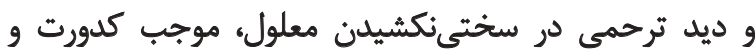

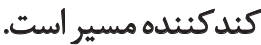

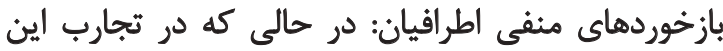

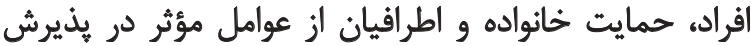

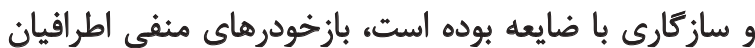

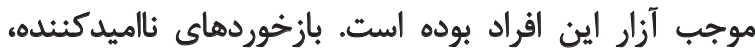

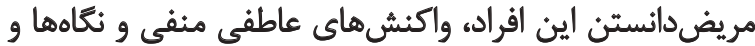

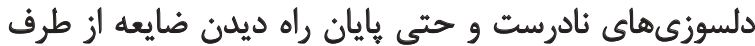

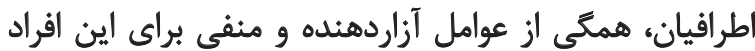

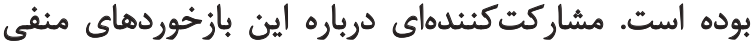

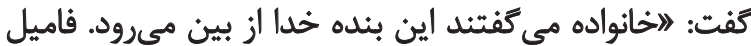

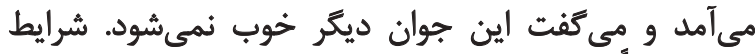

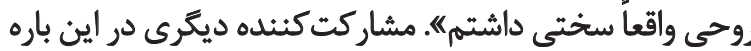

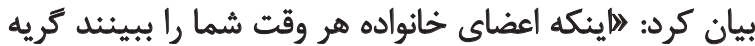

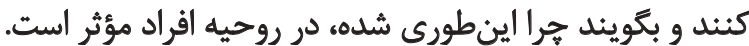

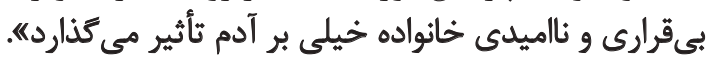
ناآكاهى از حمايت صحيح: در نقطه مقابل حمايتهاي صحيح

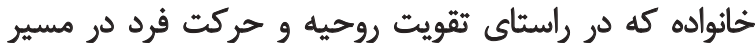

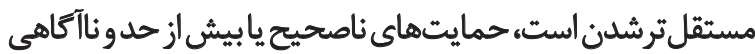




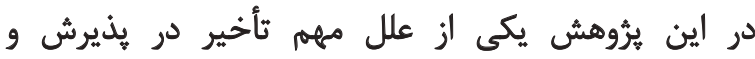

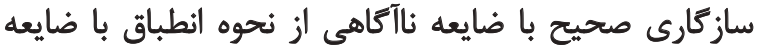

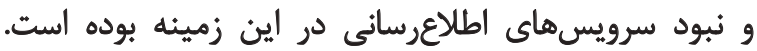

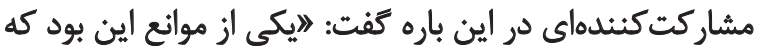

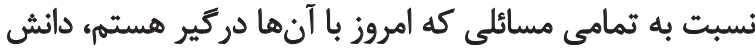

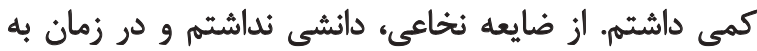

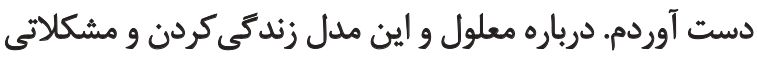

كه مدام من را ترفتار مى كرد، دانشى نداشتميه.

A

نتايج حاصل از استخراج تجارب بيماران ضايعه نخاعى

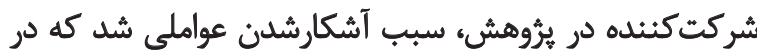

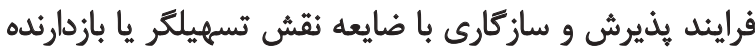

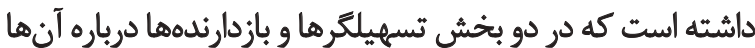

بحث مي شود.

تسميلكوها

در تجارب افراد، دريافت حمايتهاى بهموقع و تداوم آن

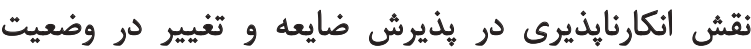

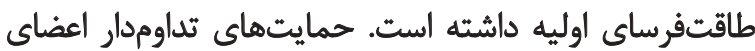

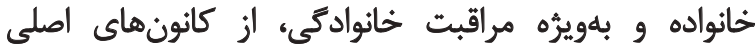

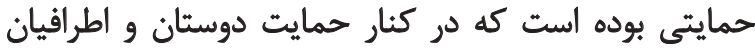

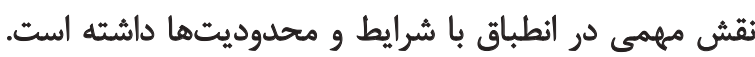

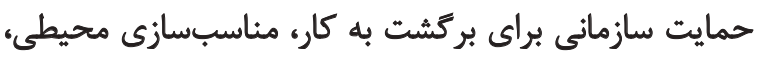

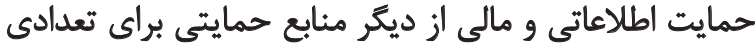

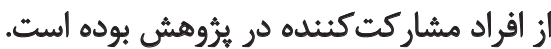

در مطالعات قبلى بر نقش و ارتباط اين حمايتها در سازگًارى

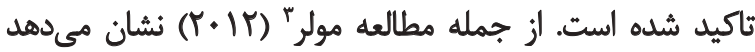

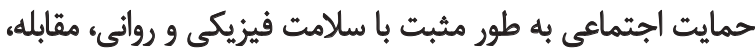

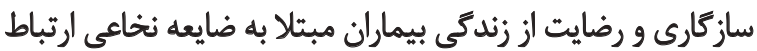

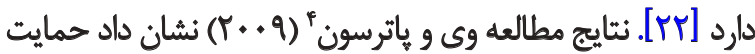

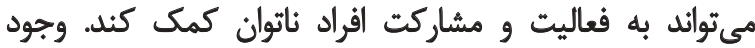

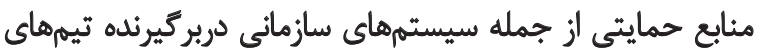

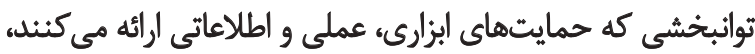

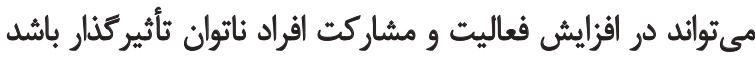

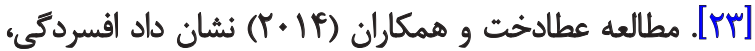

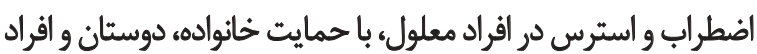

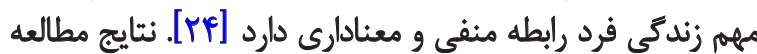

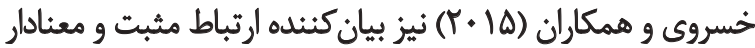

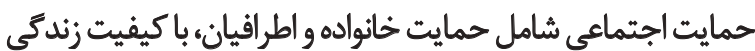

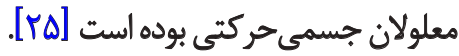

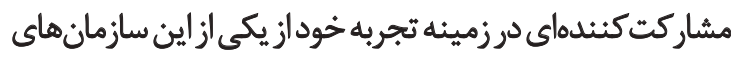

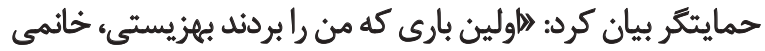

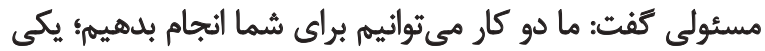

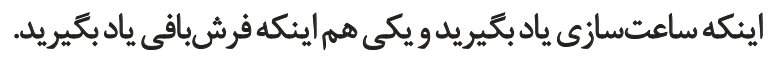

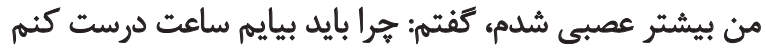

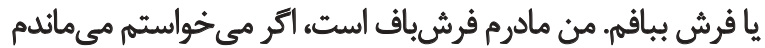

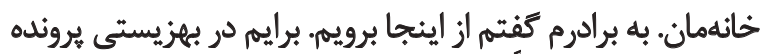

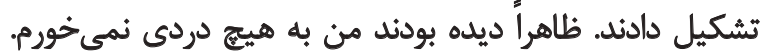

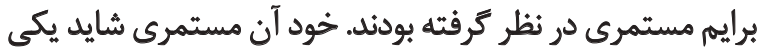

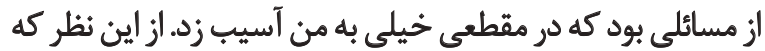
من احساس كردم روى من قيمت كنداشتندها. انتظار مشاركت كنيدكان از سازمانهاى حمايتخر، انتظار درى

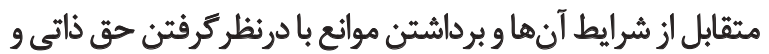

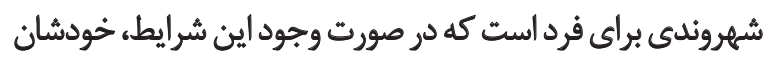

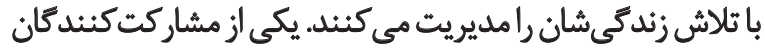

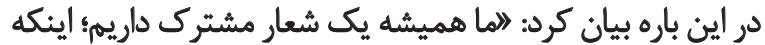

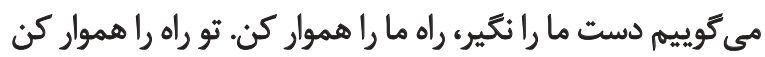

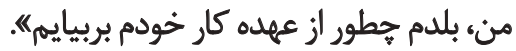

مشكلات مرتبط با سلامت: مشكلات ثانويه متعاقب آسيب

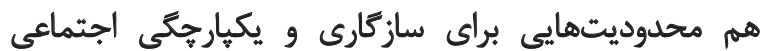

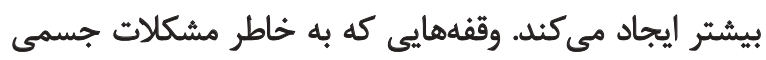

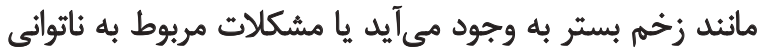

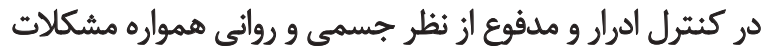

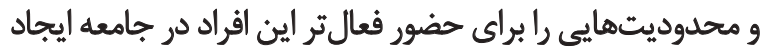

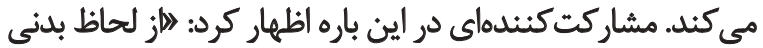

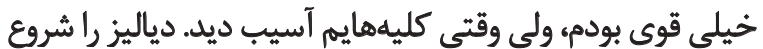
كردم، خيلى از لحاظ جسمى از تحليل رفتمهي

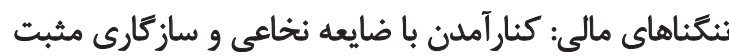

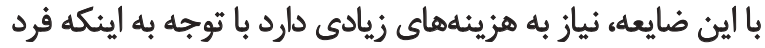

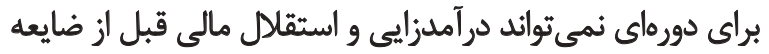

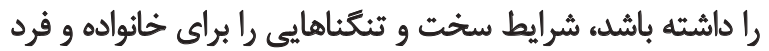

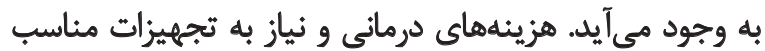

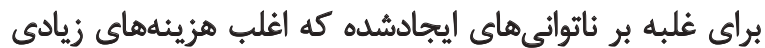

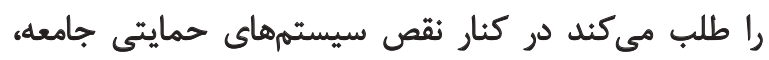

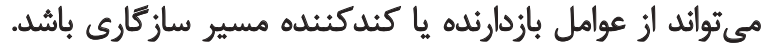

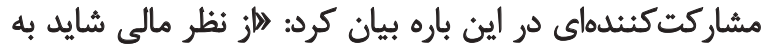

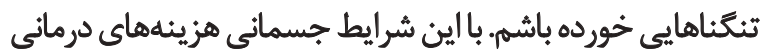

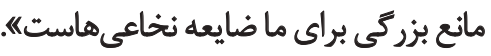
ناآكاهى معلولان: يكى از موانعى كه بذيرش و إنائ انطباق درست

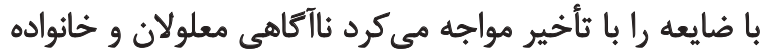

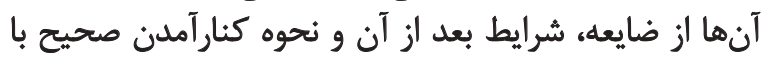
ضايعه بوده است؛ به طورى كه از نظر اغلب آن مشاركت كنيندكان 


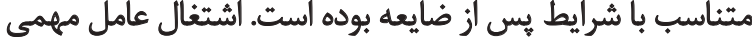

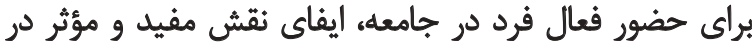

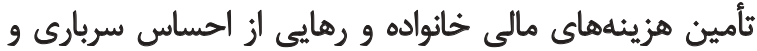

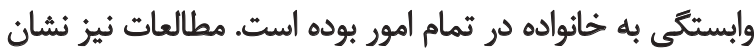

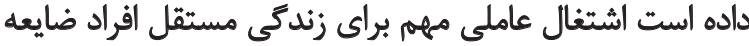

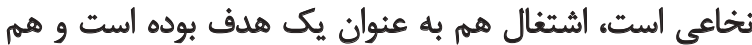

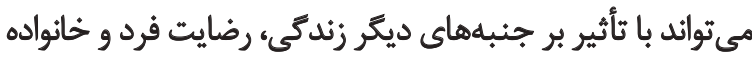

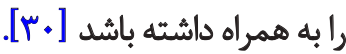

عضويت فعال در كروهها و انجمنهاى مربوط به بيماران ضايعه

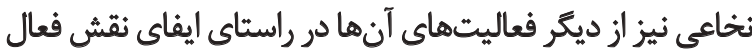

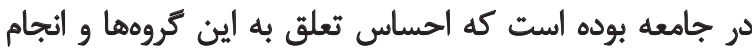

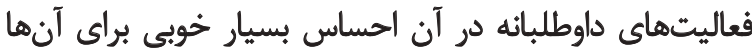

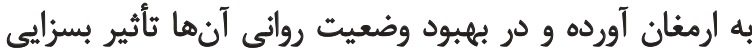

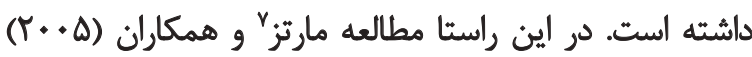
نشان ميدهد افراد ضايعه نخاعى كه مسئوليت سرويس مائهائ

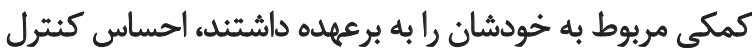

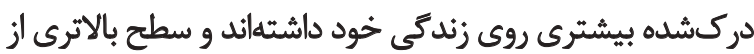

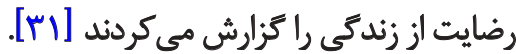

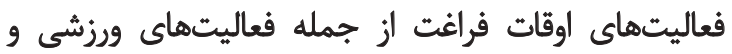

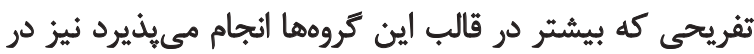

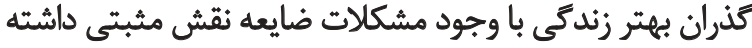

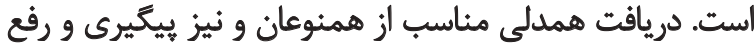

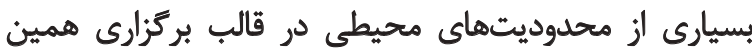
فعاليثها نيز نقش مثبتى داشته است.

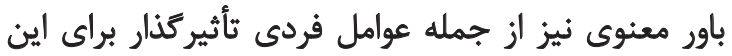

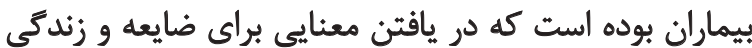

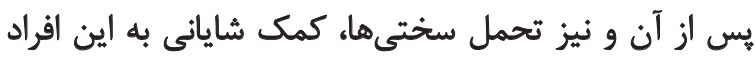

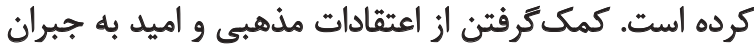

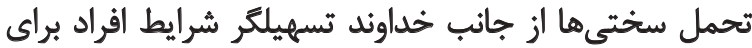

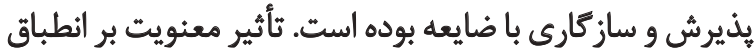

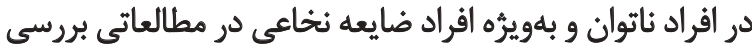

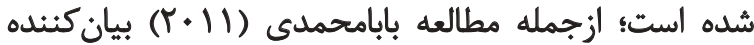

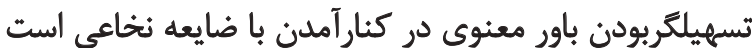

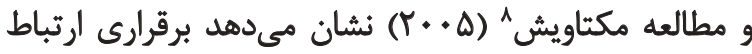

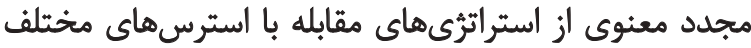

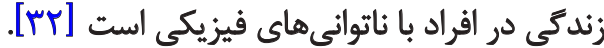
نكرش مثبت از ديكر عوامل تسهيلكر يس إز ضايعه، علاوه

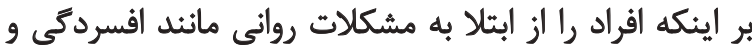

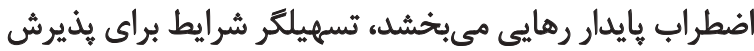

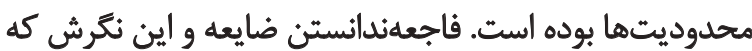

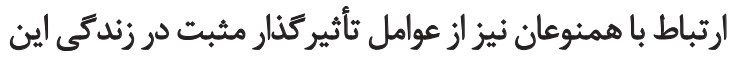

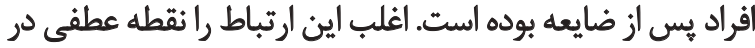

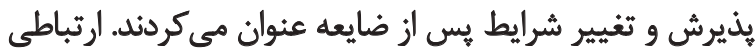

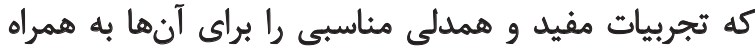

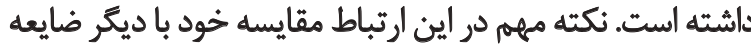

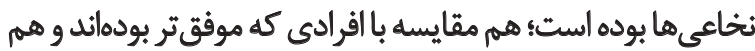

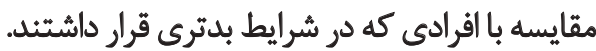

مبناى اثربخشى روابط با افراد مشابه ديكر را مىتوان با فيا

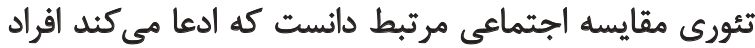

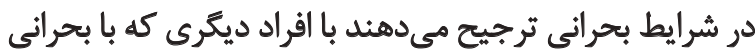

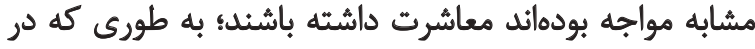

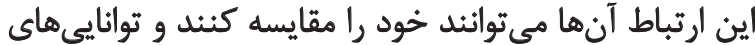

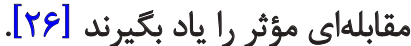

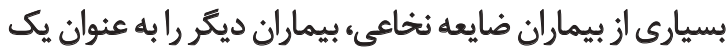

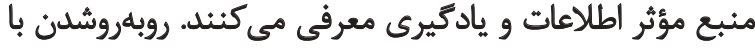

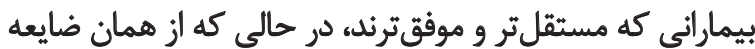

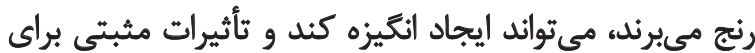

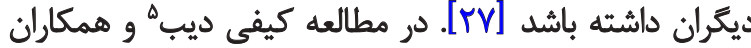

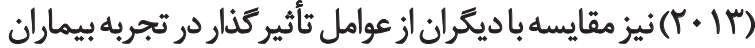

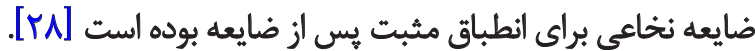

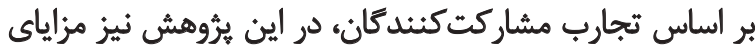

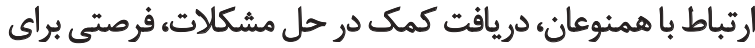

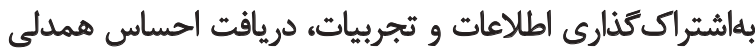

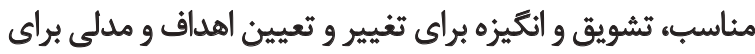
تعاملات اجتماعى بوده است. تيتويق

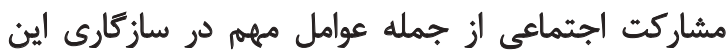

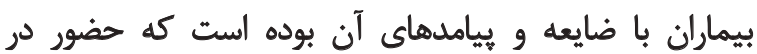

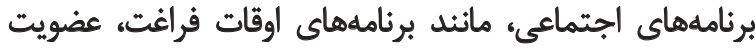

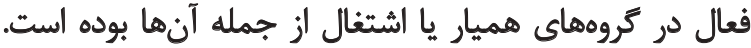

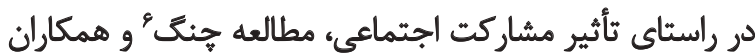

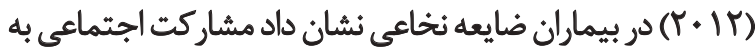

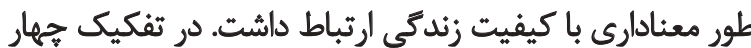

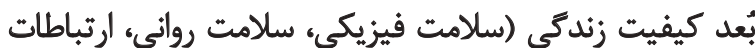

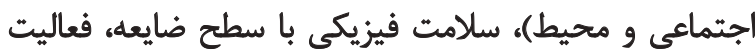

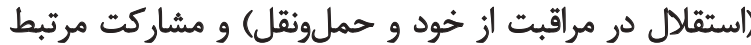

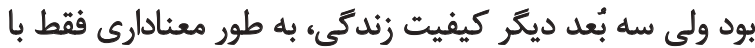

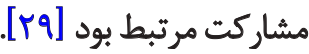
از جمله فعاليتهاى اصلى مشاركتكنئدكان در راستاى

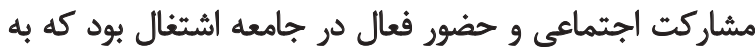

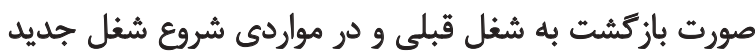




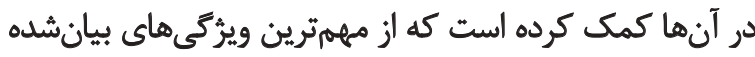

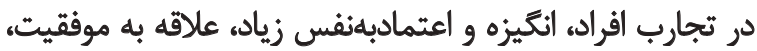

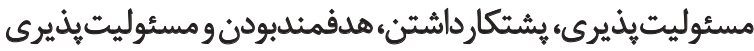

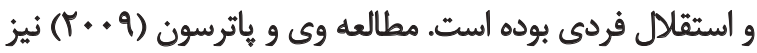

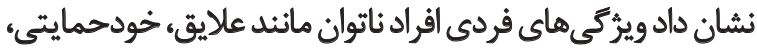

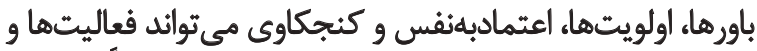

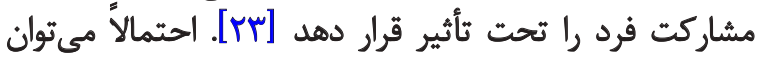

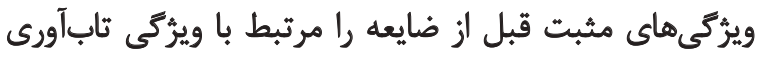

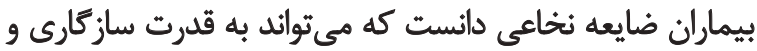
بركشت به سطح زندگى قبلى آنها نها كمك كند.

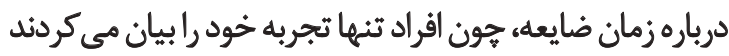

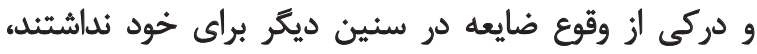

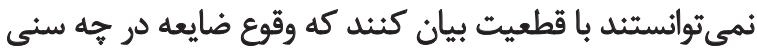

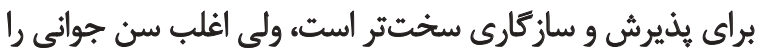

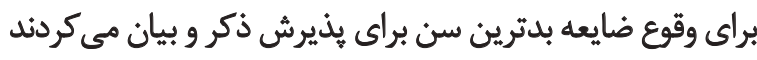

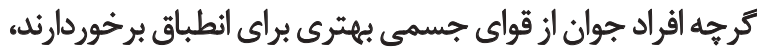

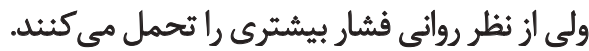

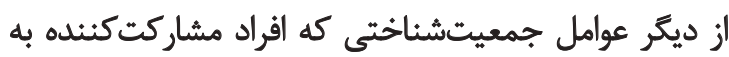

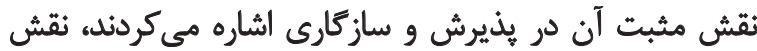

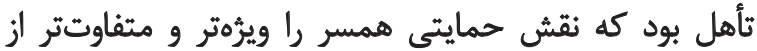

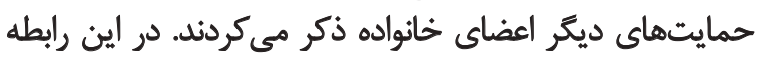

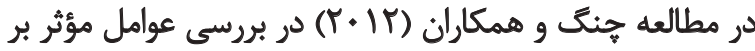

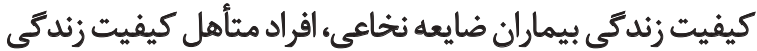

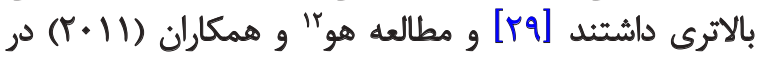

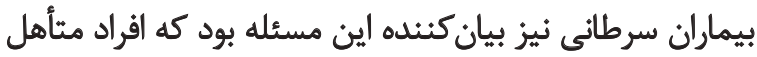

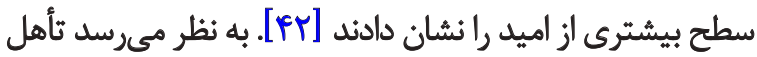

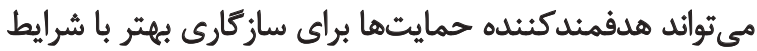

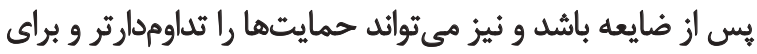

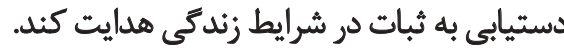

از عوامل زمينهاي مربوط به حادثه، درباره شدت و سطح ضايعه،

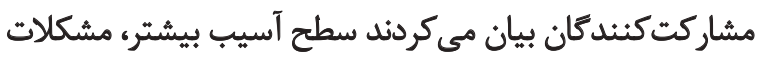

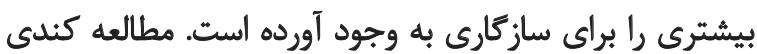

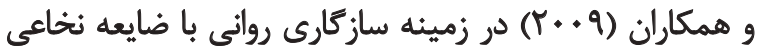

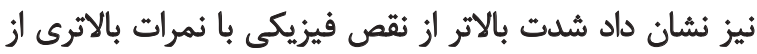

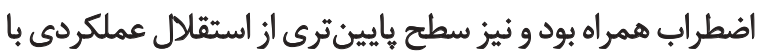

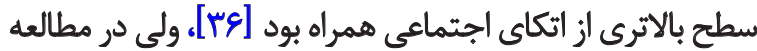

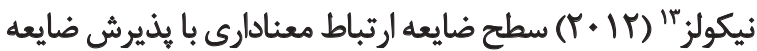

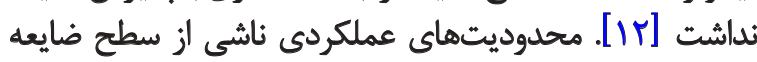

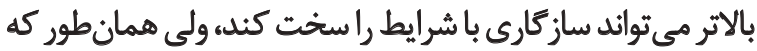
در تجربه مشاركت كنند

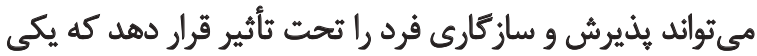

12. Ho

13. Nicholls

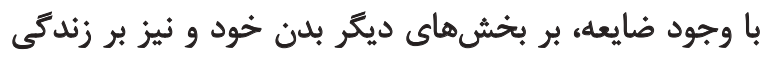

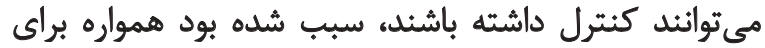

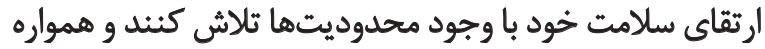
به بهببود شرايط اميدوار باشند.

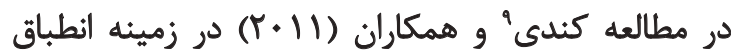

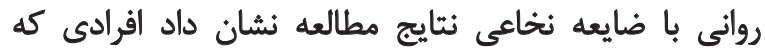

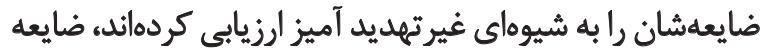

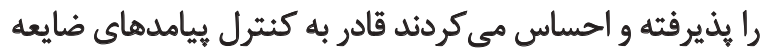

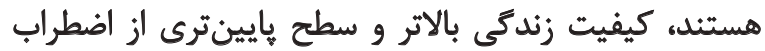

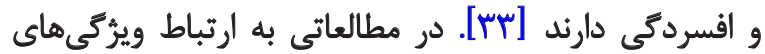

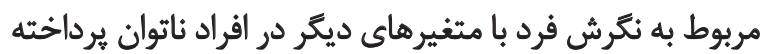

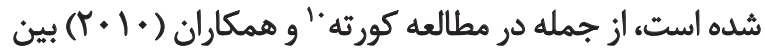

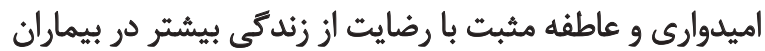

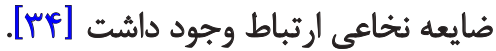

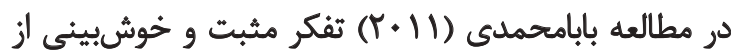

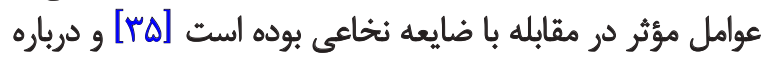

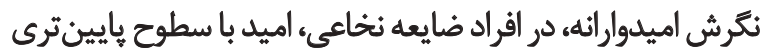

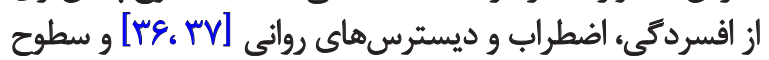

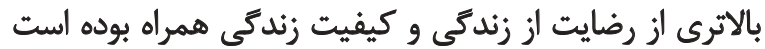

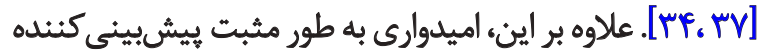

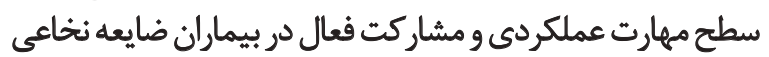

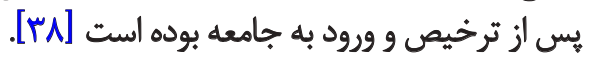

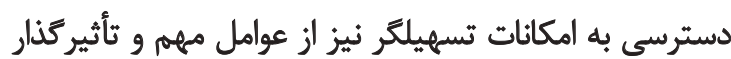

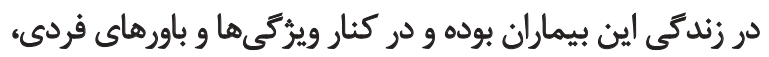

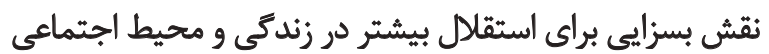

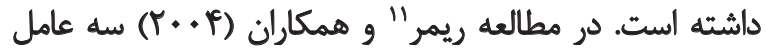

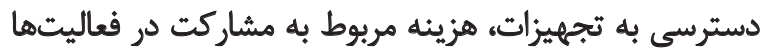

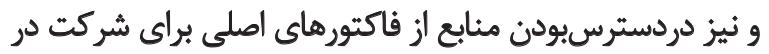

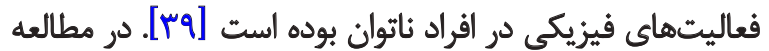

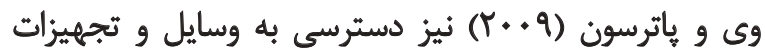

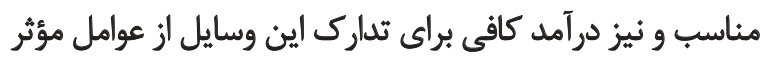

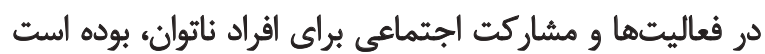

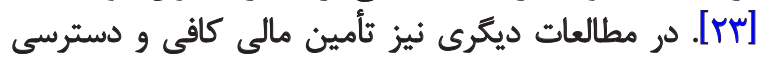

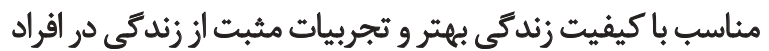

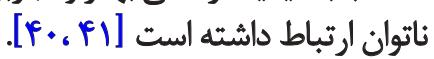
عوامل زمينهاى مانند ويرُكى هاى فردى قبل از ضايعه، سن

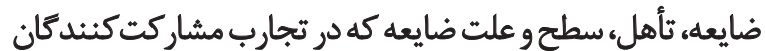

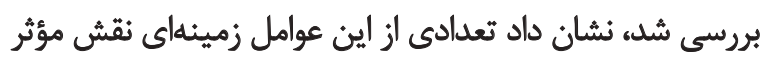

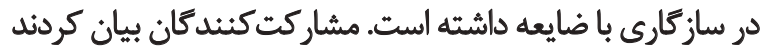

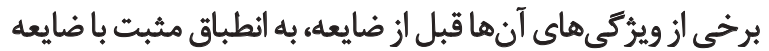

\section{Kennedy}

10. Kortte

11. Rimmer 
ترمز در فرايند سازگارى عمل مى كند.

در تجارب افراد عوارضى مانند زخم بستر، مشكلات كليه

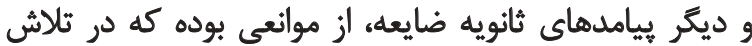

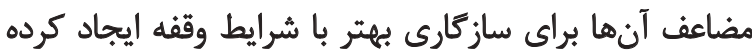

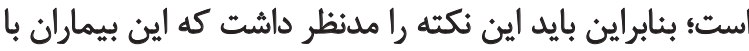

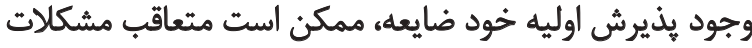

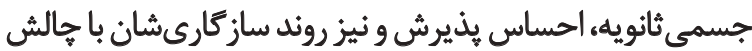

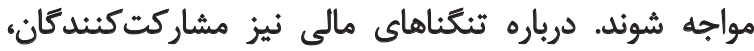

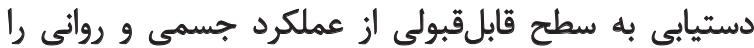

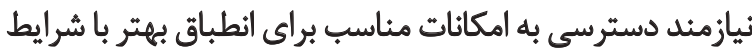

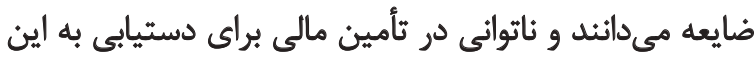

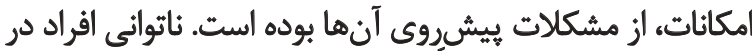

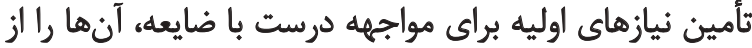

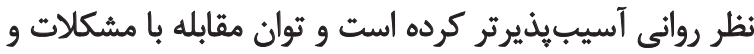
درنهايت سازكارى بهتر با ضايعه را كاهش مي كيدهد.

آكاهى ناكافى درباره ضايعه و عواقب آن و تَّونكى مواجهه

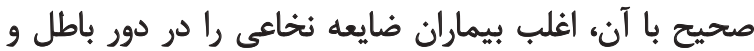

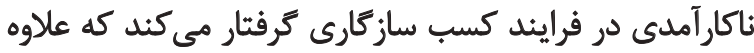

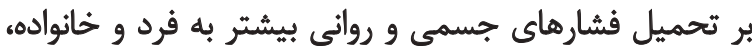

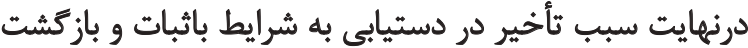

$$
\text { به روال عادى زندكى مي شئي درد. }
$$

در يرؤهش هاي قبلى اغلب موانع ساز كارى، مشاركت اجتماعي

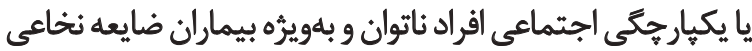

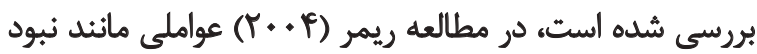

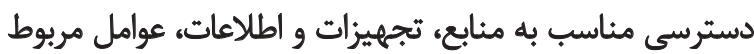

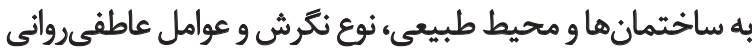

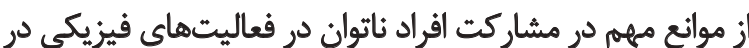

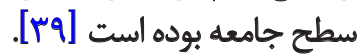

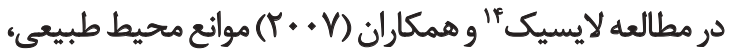

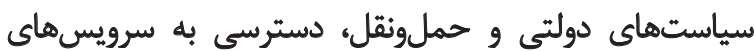

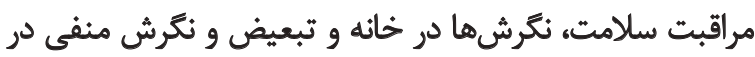

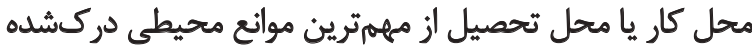

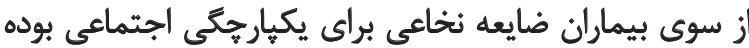

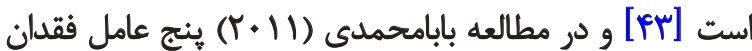

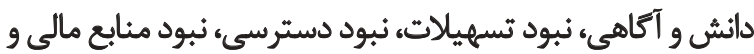

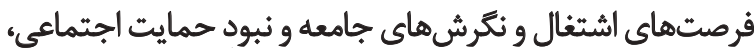

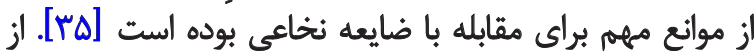

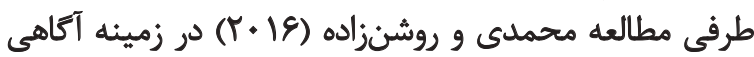

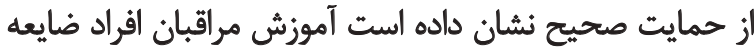

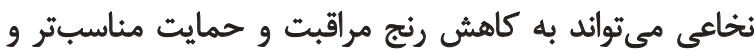

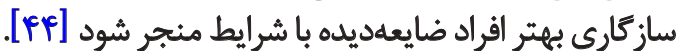

از آنها مي تواند سطح ضايعه باشد؛ بنابراين اين عامل را بهتنهايى نمى توان تعيين كنيده شرايط دانست.

باززدارئدهها

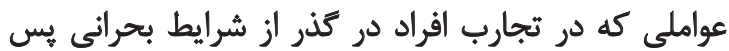

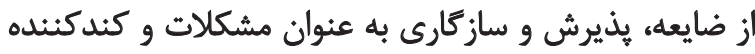

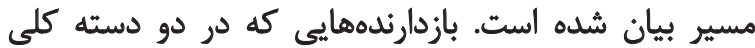
باورهاى فرهنتى و اجتماعى و موانع ساختارى و و زمينهاي

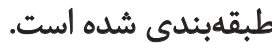

باورهاي فرهنكي و اجتماعى حاكم بر جامعه و حتى خانوادها

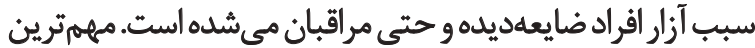

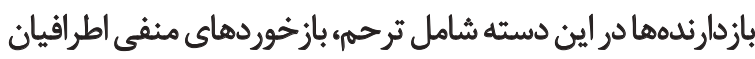

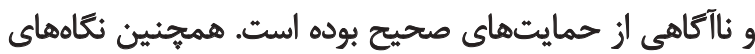

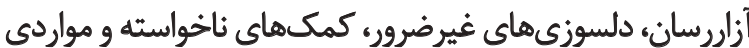

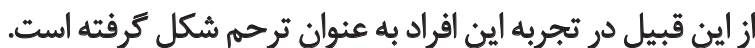

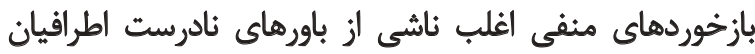

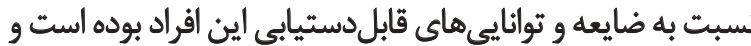

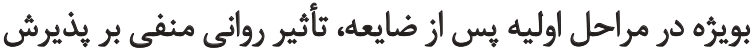
و سازگًارى با ضايعه داشته است.

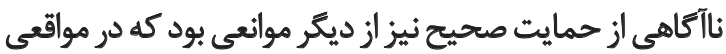

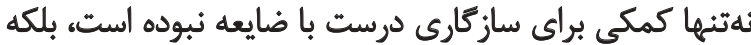

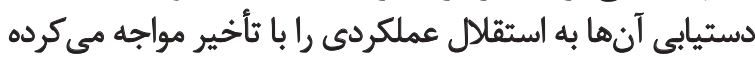

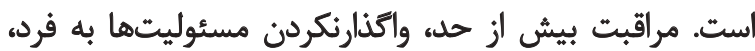

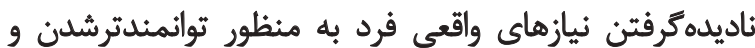

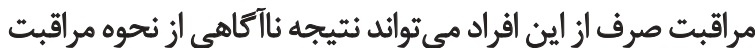

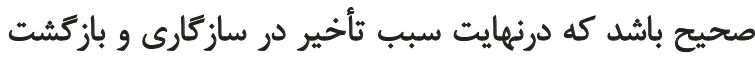

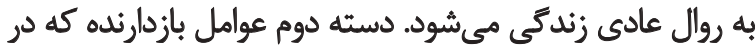

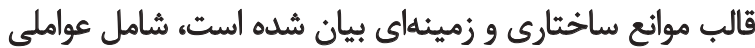

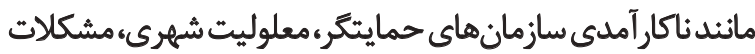

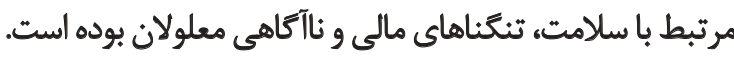
ناكارآمدى سازمانهاى حمايتكر در درك درست ازئن نيازهاي

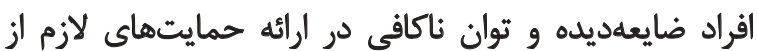

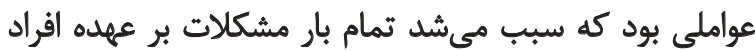

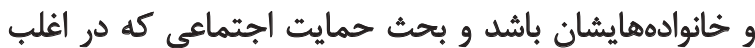

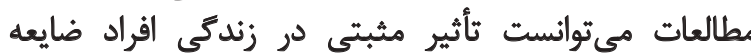

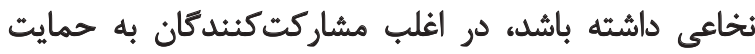

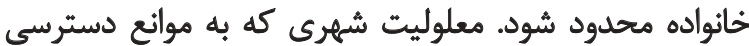

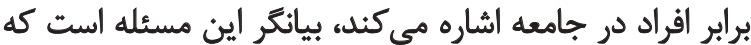

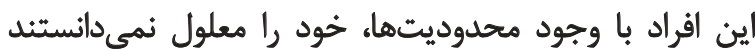

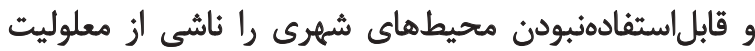

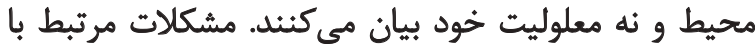
سلامت كه از عوارض ثانويه ضايعه است نيز در مواقعى به به عنوان مرني 


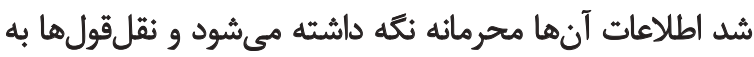

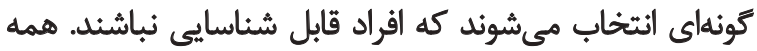

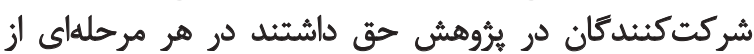
مطالعه انصراف دهند.

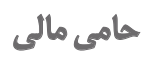

اين مقاله از رساله دكتراي نويسنده اول در كروه مشاوره

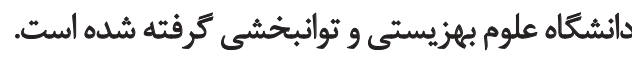

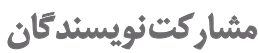

همه نويسئدكان در آمادهسازى اين مقاله مشاركت كردهاند..

$$
\text { ت تعارض منأق }
$$

بنا بر اظطهار نويسندكان، اين مقاله تعارض منافع ندارد.

$$
\text { تشكر وقدردائى }
$$

بدينوسيله از همكارى صميمانه انجمن حمايت از معلولان ضايعه

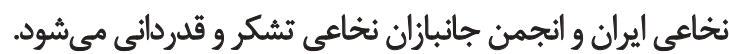

\section{نتيجليَيرى}

نتايج استخراجشده از تجارب بيماران ضايعه نخاعى نشان

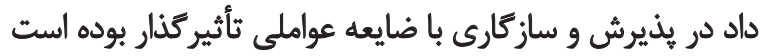

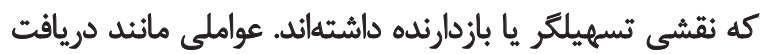

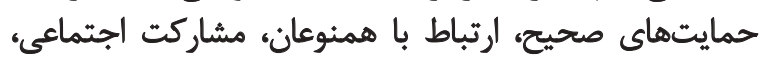

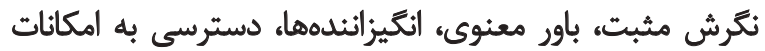

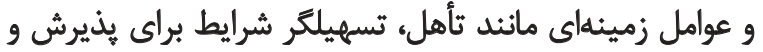

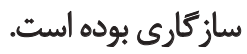

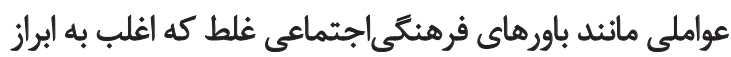

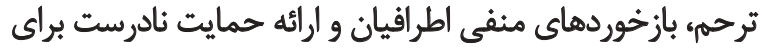

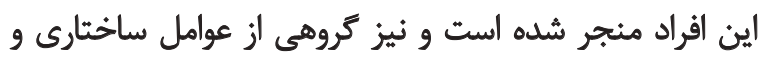

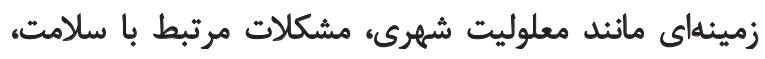

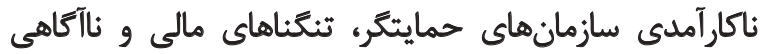

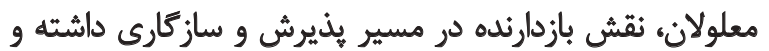

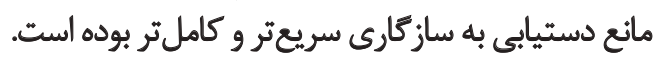

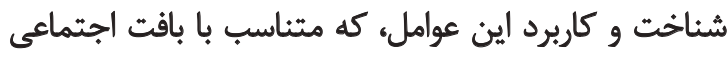

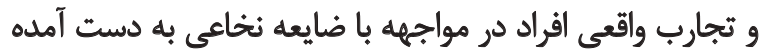

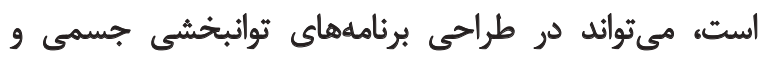

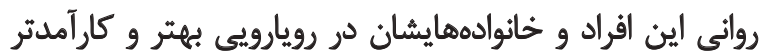

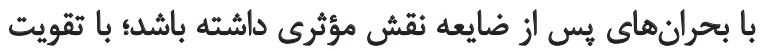

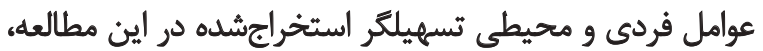

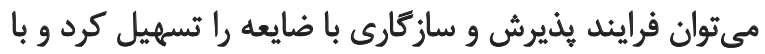

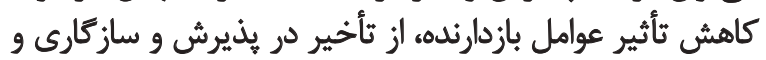

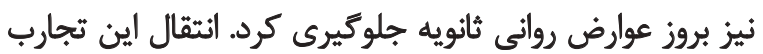

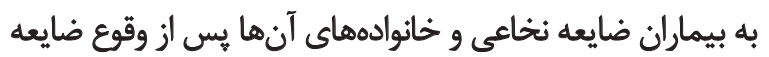

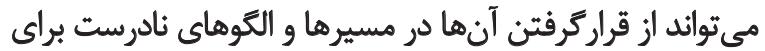

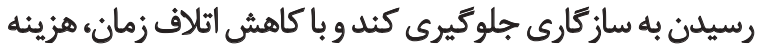

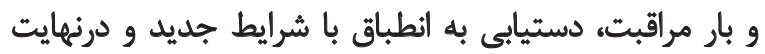
بازگشت به جامعه اين بيماران را تسهيل بان كند.

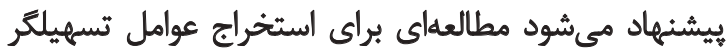

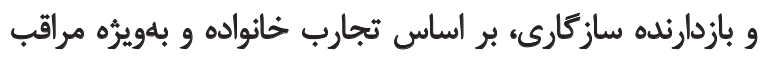

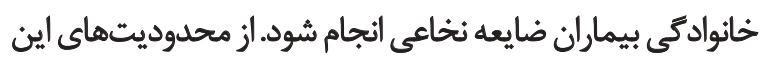

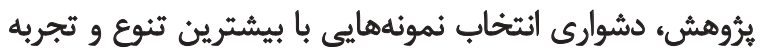

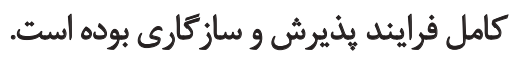

ملاحظات اخلاقى بيروى أز اصول اخلاق بثوهش كميته اخلاق دانشكاه علوم بهزيستى و توانبخشى اين مطالعه

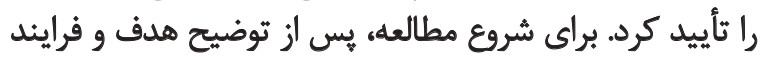

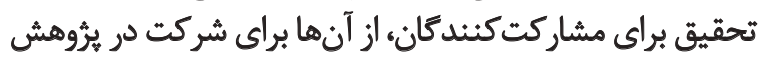
رضايت كتبى كرفته شد. به مشاركت كنندكان انمان اطمينان داده 


\section{References}

[1] Benavente A, Palazón R, Tamayo R, Morán E, Alaejos J, Alcaraz A. Assessment of disability in spinal cord injury. Disability and Rehabilitation. 2003; 25(18):1065-70. [DOI:10.1080/0963828 031000137775] [PMID]

[2] Jazayeri SB, Beygi S, Shokraneh F, Hagen EM, Rahimi-Movaghar V. Incidence of traumatic spinal cord injury worldwide: A systematic review. European Spine Journal. 2015; 24(5):90518. [DOI:10.1007/s00586-014-3424-6] [PMID]

[3] Simpson LA, Eng JJ, Hsieh JT, Spinal Cord Injury Rehabilitation Evidence (SCIRE) Research Team. The health and life priorities of individuals with spinal cord injury: A systematic review. Journal of Neurotrauma. 2012; 29(8):1548-55. [DOI:10.1089/ neu.2011.2226] [PMID] [PMCID]

[4] McKinley WO, Jackson AB, Cardenas DD, Michael J. Long-term medical complications after traumatic spinal cord injury: A regional model systems analysis. Archives of Physical Medicine and Rehabilitation. 1999; 80(11):1402-10. [DOI:10.1016/ S0003-9993(99)90251-4]

[5] Anderson D, Dumont S, Azzaria L, Bourdais ML, Noreau L. Determinants of return to work among spinal cord injury patients: A literature review. Journal of Vocational Rehabilitation. 2007; 27(1):57-68.

[6] North N. The psychological effects of spinal cord injury: A review. Spinal Cord. 1999; 37(10):671-9. [DOI:10.1038/ sj.sc.3100913] [PMID]

[7] Craig A, Tran Y, Lovas J, Middleton J. Spinal cord injury and its association with negative psychological states. International Journal of Psychological Rehabilitation. 2008; 12(2):115-21.

[8] Migliorini C, Tonge B, Taleporos G. Spinal cord injury and mental health. Australian and New Zealand Journal of Psychiatry. 2008; 42(4):309-14. [DOI:10.1080/00048670801886080] [PMID]

[9] Post M, Van Leeuwen C. Psychosocial issues in spinal cord injury: A review. Spinal Cord. 2012; 50(5):382-9. [DOI:10.1038/ sc.2011.182] [PMID]

[10] Bonanno GA, Westphal M, Mancini AD. Resilience to loss and potential trauma. Annual Review of Clinical Psychology. 2011; 7:511-35. [DOI:10.1146/annurev-clinpsy-032210-104526] [PMID]

[11] Bonanno GA. Loss, trauma, and human resilience: Have we underestimated the human capacity to thrive after extremely aversive events. American Psychologist. 2004; 59(1):20-8. [DOI:10.1037/0003-066X.59.1.20] [PMID]

[12] Nicholls E, Lehan T, Plaza SLO, Deng X, Romero JLP, Pizarro JAA, et al. Factors influencing acceptance of disability in individuals with spinal cord injury in Neiva, Colombia, South America. Disability and Rehabilitation. 2012; 34(13):1082-8. [DOI:10 .3109/09638288.2011.631684] [PMID]

[13] Li L, Moore D. Acceptance of disability and its correlates. The Journal of Social Psychology. 1998; 138(1):13-25. [DOI:10.1080/00224549809600349] [PMID]
[14] Peter C, Müller R, Cieza A, Geyh S. Psychological resources in spinal cord injury: A systematic literature review. Spinal Cord. 2012; 50(3):188-201. [DOI:10.1038/sc.2011.125] [PMID]

[15] Stanton AL, Revenson TA, Tennen H. Health psychology: Psychological adjustment to chronic disease. Annual Review of Psychology. 2007; 58:565-92. [DOI:10.1146/annurev. psych.58.110405.085615] [PMID]

[16] Keany KC, Glueckauf RL. Disability and value change: An overview and reanalysis of acceptance of loss theory. Rehabilitation Psychology. 1993; 38(3):199-210. [DOI:10.1037/h0080297]

[17] Kennedy P, Duff J, Evans M, Beedie A. Coping effectiveness training reduces depression and anxiety following traumatic spinal cord injuries. British Journal of Clinical Psychology. 2003; 42(1):41-52. [DOI:10.1348/014466503762842002] [PMID]

[18] Kennedy P, Lude P, Taylor N. Quality of life, social participation, appraisals and coping post spinal cord injury: A review of four community samples. Spinal Cord. 2006; 4(2):94-105. [DOI:10.1038/sj.sc.3101787]

[19] Chevalier Z, Kennedy P, Sherlock O. Spinal cord injury, coping and psychological adjustment: A literature review. Spinal Cord. 2009; 47(11):778-82. [DOI:10.1038/sc.2009.60] [PMID]

[20] Pope C, van Royen P, Baker R. Qualitative methods in research on healthcare quality. Quality and Safety in Health Care. 2002; 11(2):148-52. [DOI:10.1136/qhc.11.2.148] [PMID] [PMCID]

[21] Carpenter D, Streubert H. Qualitative research in nursing: Advancing the humanistic imperative. Philadelphia: Lippincott Williams \& Wilkins; 2011.

[22] Müller R, Peter C, Cieza A, Geyh S. The role of social support and social skills in people with spinal cord injury: A systematic review of the literature. Spinal Cord. 2012; 50(2):94-106. [DOI:10.1038/sc.2011.116] [PMID]

[23] Wee J, Paterson M. Exploring how factors impact the activities and participation of persons with disability: Constructing a model through grounded theory. The Qualitative Report. 2009; 14(1):165-200.

[24] Atadokht A, Jokar Kamal Abadi N, Hoseini Kiasari T, Basharpoor S. [The role of perceived social support in predicting psychological disorders in people with physical disability and its comparison with normal subjects (Persian)]. Archives of Rehabilitation. 2014; 15(3):27-35.

[25] Khosravi N, Raheb GH, Arshi M, Eghlima A. [The relaonship evaluaon between physical disabled's social support and life quality in Raad's Educaon Centers (Persian)]. Archives of Rehabilitation. 2015; 16(2):176-85.

[26] Thoits PA, Hohmann AA, Harvey MR, Fletcher B. Similar-other support for men undergoing coronary artery bypass surgery. Health Psychology. 2000; 19(3):264-73. [DOI:10.1037/02786133.19.3.264] [PMID]

[27] Boluki S, Dadgoo M, Kamali M. The effect of knowledge \& learning on perception and experience of independence among patients with spinal cord injury. Physical TreatmentsSpecific Physical Therapy Journal. 2014; 4(1):20-4.

[28] Dibb B, Ellis-Hill C, Donovan-Hall M, Burridge J, Rushton D. Exploring positive adjustment in people with spinal cord 
injury. Journal of Health Psychology. 2014; 19(8):1043-54. [DOI:10.1177/1359105313483158] [PMID]

[29] Chang F-H, Wang $\mathrm{Y}-\mathrm{H}$, Jang $\mathrm{Y}$, Wang C-W. Factors associated with quality of life among people with spinal cord injury: Application of the international classification of functioning, disability and health model. Archives of Physical Medicine and Rehabilitation. 2012; 93(12):2264-70. [DOl:10.1016/j.apmr.2012.06.008] [PMID]

[30] Anderson CJ, Vogel LC. Employment outcomes of adults who sustained spinal cord injuries as children or adolescents. Archives of Physical Medicine and Rehabilitation. 2002; 83(6):791-801. [DOI:10.1053/apmr.2002.32742]

[31] Martz E, Livneh H, Priebe M, Wuermser LA, Ottomanelli L. Predictors of psychosocial adaptation among people with spinal cord injury or disorder. Archives of Physical Medicine and Rehabilitation. 2005; 86(6):1182-92. [DOI:10.1016/j. apmr.2004.11.036] [PMID]

[32] Mactavish J, Iwasaki Y. Exploring perspectives of individuals with disabilities on stress-coping. Journal of Rehabilitation. 2005; 71(1):20-31.

[33] Kennedy P, Nolan M, Smithson E. Psychological adjustment to spinal cord injury in Ireland: Quality of life, appraisals and coping. The Irish Journal of Psychology. 2011; 32(3-4):116-29. [DOI:10.1080/03033910.2011.613187]

[34] Kortte KB, Gilbert M, Gorman P, Wegener ST. Positive psychological variables in the prediction of life satisfaction after spinal cord injury. Rehabilitation Psychology. 2010; 55(1):40-7. [DOI:10.1037/a0018624] [PMID]

[35] Babamohamadi H, Negarandeh R, Dehghan Nayeri N. Barriers to and facilitators of coping with spinal cord injury for Iranian patients: A qualitative study. Nursing \& Health Sciences. 2011; 13(2):207-15. [DOI:10.1111/j.1442-2018.2011.00602.x] [PMID]

[36] Kennedy P, Evans M, Sandhu N. Psychological adjustment to spinal cord injury: The contribution of coping, hope and cognitive appraisals. Psychology Health and Medicine. 2009; 14(1):17-33. [DOI:10.1080/13548500802001801] [PMID]

[37] Kennedy P, Lude P, Elfström M, Smithson E. Appraisals, coping and adjustment pre and post $\mathrm{SCl}$ rehabilitation: A 2-year follow-up study. Spinal Cord. 2012; 50(2):112-8. [DOI:10.1038/ sc.2011.127] [PMID]

[38] Kortte KB, Stevenson JE, Hosey MM, Castillo R, Wegener ST. Hope predicts positive functional role outcomes in acute rehabilitation populations. Rehabilitation Psychology. 2012; 57(3):248-55. [DOI:10.1037/a0029004] [PMID]

[39] Rimmer JH, Riley B, Wang E, Rauworth A, Jurkowski J. Physical activity participation among persons with disabilities: Barriers and facilitators. American Journal of Preventive Medicine. 2004; 26(5):419-25. [DOI:10.1016/j.amepre.2004.02.002] [PMID]

[40] Inman C. Effectiveness of spinal cord injury rehabilitation. Clinical Rehabilitation. 1999; 13(1 suppl):25-31. [DOI:10.1191/ 026921599674943310] [PMID]
[41] Manns PJ, Chad KE. Components of quality of life for persons with a quadriplegic and paraplegic spinal cord injury. Qualitative Health Research. 2001; 11(6):795-811. [DOI:10.1177/104 973201129119541] [PMID]

[42] Ho S, Rajandram RK, Chan N, Samman N, McGrath C, Zwahlen RA. The roles of hope and optimism on posttraumatic growth in oral cavity cancer patients. Oral Oncology. 2011; 47(2):1214. [DOI:10.1016/j.oraloncology.2010.11.015] [PMID]

[43] Lysack C, Komanecky M, Kabel A, Cross K, Neufeld S. Environmental factors and their role in community integration after spinal cord injury. Canadian Journal of Occupational Therapy. 2007; 74(5 suppl):243-54. [DOI:10.1177/0008417407074 0S304] [PMID]

[44] Mohammadi S, Roshanzadeh M. [The effect of educational intervention based on orem self-care model on family caregiver's burden of patients with spinal cord injuries (Persian)] Archives of Rehabilitation. 2016; 17(1): 55-63. [DOI:10.20286/ jrehab-170152] 